\title{
Numerical study of propulsion system performance during ship acceleration
}

\author{
P. Mizythras*, E. Boulougouris \& G. Theotokatos \\ Department of Naval Architecture, Ocean and Marine Engineering \\ University of Strathclyde, Glasgow G4 OLZ, United Kingdom
}

\begin{abstract}
Ship acceleration manoeuvre is important in terms of safety and engine performance. Head seaways are one of the most challenging conditions for the ship propulsion. A detailed simulation of the propulsion system's transient response during dynamic acceleration in harsh conditions can result in a thorough investigation of the engine performance, a better management of control system and the monitoring of engine limiters application in real conditions. For the overall propulsion system performance assessment during ship acceleration, a computational tool has been developed that comprises sub-systems for the simulation of engine, turbocharger, propeller components and their interaction. The developed tool has been validated against available shop and sea trials data and then it has been tested for the simulation of propulsion system performance during acceleration in dynamic conditions. Based on the simulations results, a sensitivity analysis has been performed for the investigation of the governor control unit limiters that apply on the engine during acceleration. As a result, the effect of engine governor limiters on the overall engine and hydrodynamic performance of the ship during acceleration is quantified and discussed.
\end{abstract}

Keywords: marine Diesel engine; transient response; ship acceleration; mean value engine modelling; engine limiters analysis.

\footnotetext{
*Corresponding Author, e-mail address: panayiotis.mizythras@strath.ac.uk
} 


\section{Introduction}

New technologies of propulsion solutions and environmental policy led the International Maritime Organization (IMO) to the definition and continuously update of the regulatory framework that defines the requirements for an efficient operation of a ship (Bazari and Longva, 2011). Moreover, as a response to the serious concerns regarding the sufficient performance of the ship propulsion system during manoeuvring or emergency conditions, IMO introduced new guidelines for the determination of the minimum required installed propulsion power (IMO, 2015). Simultaneously, procedures have been established to analyse speed trial data, improving ship performance assessment for the estimation of the Energy Efficiency Design index (EEDI) (ITTC, 2014; ISO, 2015).

Considering the importance of the installed power to the ship navigation during marine design, various projects and simulations tools have been deployed, for investigating the performance of the propulsion system. The taxonomy of models that have been used for the engine simulation ranges from simple lookup tables in off-design operation conditions (Shi et al., 2009) to 0-D/1-D thermodynamic models for the engine performance prediction (Hountalas, 2000). For the latter, multizone combustion models can facilitate the NOx emissions prediction (Raptotasios et al., 2015). Moreover, CFD models in conjunction with skeletal chemical kinetic mechanism models are adopted for the efficient simulation of pollutants formation under large-bore two-stroke marine Diesel engines (Mun Pang et al., 2016; 2017).

A comprehensive model has been proposed for the prediction of large, turbocharged, two-stroke engine, providing satisfactory prediction of engine's performance by using a simplified mean-value approach, governing the propulsion system along with the hydrodynamic principles (Woodward and Latorre, 1984). Thence, this approach has been applied in many cases for the simulation of marine engines performance (Hendricks, 1986; Schulten and Stapersma, 2003; Eriksson, 2007; Theotokatos, 2008; Dimopoulos et al., 2014), whilst subsequently, hybrid models have been developed, providing more details for the engine in-cylinder parameters (Baldi et al., 2015; Tang et al. 2017). 


\section{Background}

Taking into account the importance of propulsion system, engine simulation models were used during the ship design phase for estimating the performance of propulsion system in real conditions. Several studies have attempted to simulate the propulsion system performance, using simplifying assumptions for the ship hull resistance through the use of a standard resistance curve (Kyrtatos et al., 1999; Theotokatos, 2010), whilst the effect of various factors, including sea state and hull fouling, have been considered for the estimation of the engine performance and the fuel consumption in transient conditions in (Theotokatos, 2010). Moreover, the performance of the coupled propellerengine system in waves was studied by (Taskar et al., 2017). Their results provide a good insight on the engine-propeller dynamics performance, with special focus to the propeller inflow velocity.

Apart from the investigation of the propulsion system performance in waves, several models have been developed for the simulation of engine performance during dynamic conditions as the ship turning motion. The 'Ship Mobility Model' was one of the first models that were developed for this purpose, using sub-models for the simulation of a propulsion system equipped with 4-stroke Diesel engine during manoeuvring (Schulten, 2005). Thence, various case studies have investigated for the behaviour of propulsion system during manoeuvring (Altosole et al., 2008; Viviani et al., 2008; Zhao et al., 2015).

For the satisfaction of the dynamic conditions imposed to the propulsion system by the sea environment, a control system is needed for the appropriate management of the propulsion system. Application of a controller to the simulation model improves the model response and system interaction in transient conditions (Blanke et al., 2006). Further controller applications include the performance of a controllable pitch propeller actuator, improving the engine response during ship propulsion (Martelli et al., 2014). A control unit is necessary also in the case that the marine propulsion system incorporates components that require an advanced computer control, like the interaction of a variable geometry turbine with a two-stroke marine Diesel engine (Xiros and Theotokatos, 2011). Therefore, the control unit is an integral part of a simulation model, aiming to the accurate prediction of engine response in dynamic sea conditions. 
Summarizing the past research efforts in this field, most of the studies focused on the ship hydrodynamic performance during manoeuvring, the importance of the controllers to the engine simulation, or the performance and emissions prediction in various operational loading cases, without investigating the interaction of the propulsion system in real transient conditions such as the ship acceleration. The ship acceleration manoeuvre is acknowledged as the most challenging condition for the marine engine and the ship propulsion system, particularly when the ship sails in head seaways (IMO, 2015). Thus, the development of a tool for the sufficiently accurate simulation of the engine transient response in respect of the hydrodynamic principles is required.

For the first time, the ship acceleration manoeuvre is modelled and the propulsion system response is investigated in various head seaways. The thorough examination of the advantages and disadvantages in the existing engine simulation models and the aim to develop a fast-computing tool for the simulation of a time-consuming manoeuvre as the ship acceleration, led to the selection of the mean-value approach as the most appropriate for the engine simulation. In addition, semi-empirical methods are used for the estimation of sea state in harsh sea conditions. These methods simplify the required input data and keep a balance between the simulation accuracy and the model setting-up complexity. Considering the importance of the propeller hydrodynamic performance during acceleration, a sub-model is implemented for the interaction of the propeller thrust and the flow speed at the propeller disk.

Simulation of ship acceleration manoeuvre results in the identification of the engine limiters importance and how their application affects the ship performance. Additionally, the developed tool provides insights to the engine thermal loading during acceleration, admitting the effect of the control unit to the propulsion system. Therefore, the engine propulsion system and the integrated controllers can be optimized further in respect of the actual ship behaviour in real harsh conditions.

\section{Propulsion System Performance Simulator}

The propulsion plant of a commercial vessel is usually composed by three main components: the main marine Diesel engine, the shafting system and the propeller. Depending on the vessel type, two- 
stroke or four-stroke turbocharged engines can be used for the propulsion of the ship, whilst one or more turbochargers are installed to increase the engine's specific power. The produced power is delivered to a rotating fixed $(\mathrm{FP})$ or controllable $(\mathrm{CP})$ pitch propeller for the ship propulsion. The shafting system comprises all the connecting shafts between engine and propeller, including the gear box that is required in case of a four-stroke engine.

Recent regulations (Bazari and Longva, 2011) in gas emissions restriction and fuel efficiency improvement have rendered the usage of alternative systems for the power production, such as the hybrid propulsion systems, the use of alternative fuels (hydrogen, natural gas, biofuels), whilst other methods for ship propulsion are used to increase the manoeuvrability of a ship (e.g. azipods, thrusters). In this study, the traditional propulsion system is investigated, consisting of a marine twostroke turbocharged Diesel engine, connected directly with a FP propeller. For the simulation of engine, turbocharger and ship propulsion system performance, a model has been developed in MATLAB $^{\circledR}$. This model can be used for investigating the ship acceleration in adverse head sea conditions.

\subsection{Engine model description}

The main engine has been modelled by following a mean value approach as it is described in (Theotokatos, 2010). Mean value models adopt the average values of various parameters and variables over one or several cycles, in order to estimate the engine performance. The main engine components, including the cylinders, the turbocharger, the scavenging air and exhaust receivers, the air cooler and the auxiliary air blower, as well as the exhaust pipe and air filter have been modelled by following thermodynamics and fluid dynamics first-principles. The interconnection between the components is handled by using working fluid mass flow rates, pressures and temperatures.

In particular, the scavenging and exhaust gas receivers have been modelled as an open thermodynamic system. The pressure, temperature and working fluid properties of the adjacent components are used in order to calculate the mass and energy flow rate in the receivers. Mass and energy conservation laws are used in order to predict the working medium mass flow rate and temperature differentials, respectively: 
$\frac{\mathrm{dm}}{\mathrm{dt}}=\dot{\mathrm{m}}_{\mathrm{in}}-\dot{\mathrm{m}}_{\text {out }}$

$\frac{\mathrm{dT}}{\mathrm{dt}}=\frac{\dot{\mathrm{Q}}_{\mathrm{hl}}+(\dot{\mathrm{m} h})_{\mathrm{in}}-(\dot{\mathrm{m} h})_{\text {out }}-(\mathrm{u} \mathrm{dm} / \mathrm{dt})}{\mathrm{mc}_{\mathrm{v}}}$

where $\dot{\mathrm{m}}$ and $(\dot{\mathrm{m} h})$ are the mass and energy flow rates at the receiver, $\dot{\mathrm{Q}}_{\mathrm{hl}}$ and $(\mathrm{u} d \mathrm{~d} / \mathrm{dt})$ are the heat losses and internal energy rate. The scavenging receiver heat losses are neglected in this model, whilst the heat transfer coefficient of exhaust gas receiver is calculated based on the Nusselt number for external forced convention around pipe (Rohsenow et al. 1998). Applying the ideal gas law in equations (1) and (2), the pressure time derivative at the receivers is:

$\frac{\mathrm{dp}}{\mathrm{dt}}=\frac{\mathrm{R}}{\mathrm{V}}\left(\mathrm{T} \frac{\mathrm{dm}}{\mathrm{dt}}+\mathrm{m} \frac{\mathrm{dT}}{\mathrm{dt}}\right)$

where $\mathrm{R}$ is the working fluid gas constant and $\mathrm{V}$ is the receiver volume.

The flow rate at the engine cylinders blocks is calculated by simulating cylinder scavenger air ports and exhaust gas valve with two consecutive orifices. The engine indicated mean effective pressure (IMEP) depends on the rack position, the maximum IMEP and the combustion efficiency, which is estimated as a function of the air to fuel ratio. Subtracting the friction mean effective pressure from the IMEP, the break mean effective pressure (BMEP) is calculated. Knowing the engine BMEP, the torque of the engine is given as follows:

$\mathrm{Q}_{\mathrm{E}}=\frac{\overline{\mathrm{p}}_{\mathrm{b}} \mathrm{V}_{\mathrm{E}}}{2 \pi \mathrm{N}_{\mathrm{E}}}$

The engine fuel consumption is controlled from the governor according to the ordered engine rotational speed ( $\mathrm{N}_{\text {gov, order }}$ ). The engine governor limiters (scavenging air and torque limiters) have been included in the PI control element that controls the fuel rack position (rpos). In addition to the traditional limiters of the engine, a speed slope limiter is applied which aims at the engine protection during the acceleration or deceleration of the ship under real operating conditions. The engine speed slope limiter aims to the application of a specific rate to the engine order speed $\left(\mathrm{N}_{\text {order }}\right)$, protecting the propulsion system overloading (Figure 1). Different speed slope limiters are defined at low and high speeds, protecting the propulsion system during acceleration beginning. Depending on the initial engine speed and the given ordered engine speed the governor selects which slope limiter is applied. Thus, a new order speed is calculated based on the sleep slope limiters until the given ordered speed 
has been achieved. The difference between order speed and the current engine speed is provided to a PI controller for the calculation of rack position change.

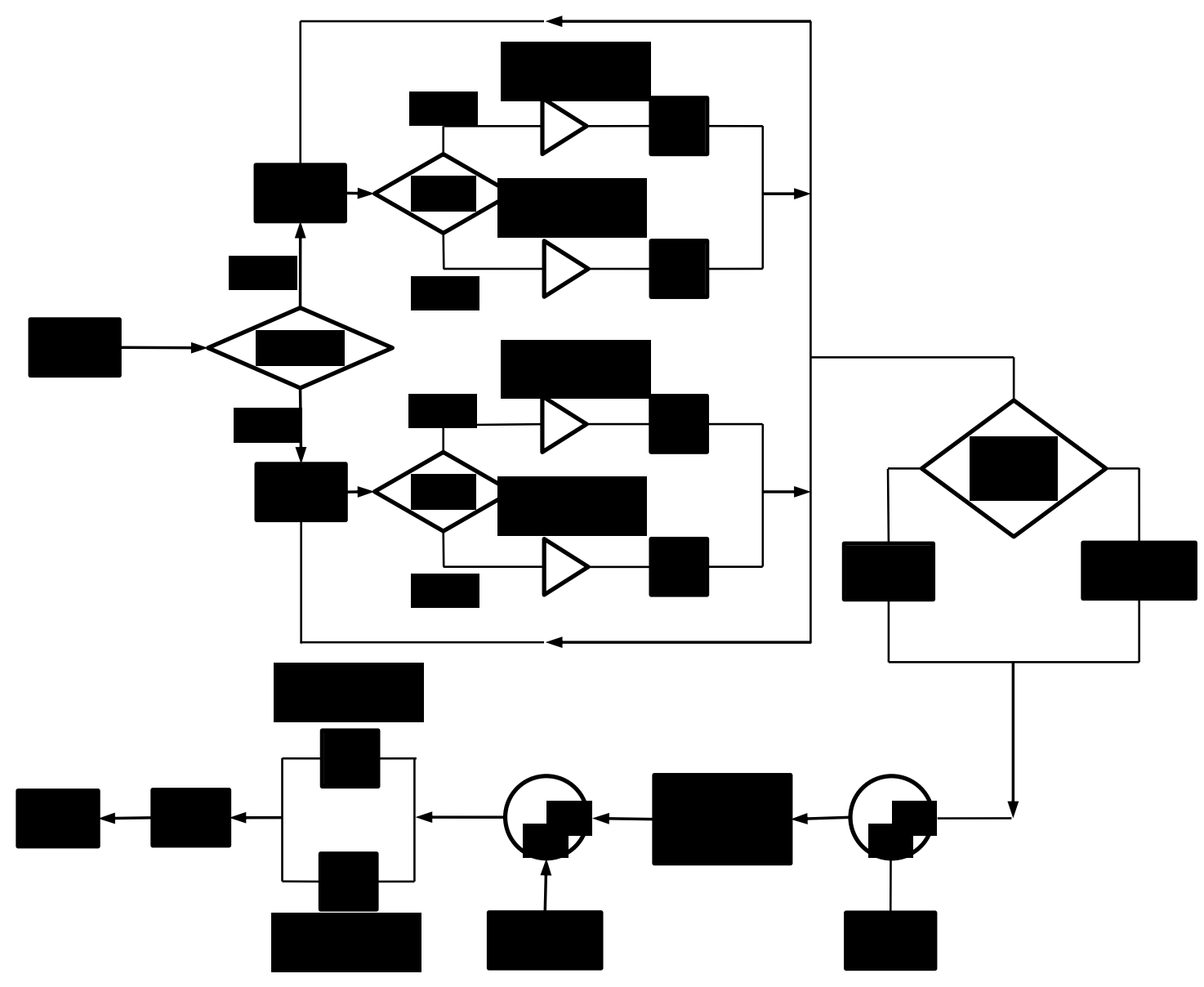

Figure 1. Flowchart of governor controller.

The turbocharger modelling is integrated by using its components' steady state performance maps. In specific, the compressor model uses as input the turbocharger speed and the compressor ratio, calculating the corrected volumetric flow rate and the isentropic efficiency based on an extended compressor model. The compressor pressure ratio is given by the following equation:

$\operatorname{pr}_{\mathrm{C}}=\frac{\mathrm{p}_{\mathrm{SR}}+\Delta \mathrm{p}_{\mathrm{AC}}-\Delta \mathrm{p}_{\mathrm{BL}}}{\mathrm{p}_{\mathrm{amb}}-\Delta \mathrm{p}_{\mathrm{AF}}}$

where the air cooler pressure drop $\Delta \mathrm{p}_{\mathrm{AC}}$ and the air filter pressure drop $\Delta \mathrm{p}_{\mathrm{AF}}$ are given as a function of air mass flow rate, whilst the blower pressure increase $\Delta \mathrm{p}_{\mathrm{BL}}$ is calculated according to the air volumetric flow rate.

Based on the compressor isentropic efficiency definition, the temperature of air exiting the compressor is given by the formula: 
$\mathrm{T}_{\mathrm{C}, \text { out }}=\mathrm{T}_{\mathrm{C}, \mathrm{in}}\left(1+\frac{\frac{\mathrm{\gamma}_{\mathrm{a}}-1}{\mathrm{p}_{\mathrm{a}}}}{\eta_{\mathrm{C}}}\right)$

The temperature of the air exiting the air cooler is calculated by the definition of air cooler effectiveness ratio:

$\varepsilon_{\mathrm{AC}}=\frac{\mathrm{T}_{\mathrm{AC}, \text { out }}-\mathrm{T}_{\mathrm{C}, \text { out }}}{\mathrm{T}_{\mathrm{AC}, \mathrm{w}}-\mathrm{T}_{\mathrm{C}, \text { out }}}$

where the air cooler effectiveness $\varepsilon_{\mathrm{AC}}$ is assumed to be a polynomial function of the air mass flow rate. The turbine mass flow rate and isentropic efficiency are estimated for the given pressure ration $\operatorname{pr}_{\mathrm{T}}$ by using as input the performance curve of the given turbine:

$\mathrm{pr}_{\mathrm{T}}=\frac{\mathrm{p}_{\mathrm{ER}}}{\mathrm{p}_{\mathrm{amb}}-\Delta \mathrm{p}_{\mathrm{AF}}}$

The compressor and the turbine torques are derived by the following formulae respectively:

$\mathrm{Q}_{\mathrm{C}}=\frac{30 \dot{\mathrm{m}}_{\mathrm{C}}\left(\mathrm{h}_{\mathrm{C}, \text { out }}-\mathrm{h}_{\mathrm{C}, \text { in }}\right)}{\pi \mathrm{N}_{\mathrm{TC}}}$

$\mathrm{Q}_{\mathrm{T}}=\frac{30 \dot{\mathrm{m}}_{\mathrm{T}}\left(\mathrm{h}_{\mathrm{ER}}-\mathrm{h}_{\mathrm{T}, \text { out }}\right)}{\pi \mathrm{N}_{\mathrm{TC}}}$

where enthalpies are calculated according to the respective fluid temperatures.

The engine and turbocharger shaft rotational speed are calculated with the following differential equations, derived by the angular momentum conservation equation at propeller and turbocharger shaft:

$\frac{\mathrm{dN}_{\mathrm{E}}}{\mathrm{dt}}=\frac{30\left(\eta_{\mathrm{sh}} \mathrm{Q}_{\mathrm{E}}-\mathrm{Q}_{\mathrm{P}}\right)}{\pi\left(\mathrm{I}_{\mathrm{E}}+\mathrm{I}_{\mathrm{sh}}+\mathrm{I}_{\mathrm{P}, \text { tot }}\right)}$

$\frac{\mathrm{dN}_{\mathrm{TC}}}{\mathrm{dt}}=\frac{30\left(\mathrm{Q}_{\mathrm{T}}-\mathrm{Q}_{\mathrm{C}}\right)}{\pi \mathrm{I}_{\mathrm{TC}}}$

The detailed mass and energy flow rate is presented in Figure 2. The input variables for the engine system sub-model are the engine speed and the rack position, estimated by using the shaft dynamics and the engine governor dynamics, respectively. In order to improve the reliability of model's performance in real conditions, the developed engine model has been validated independently against to the shop trials data. 


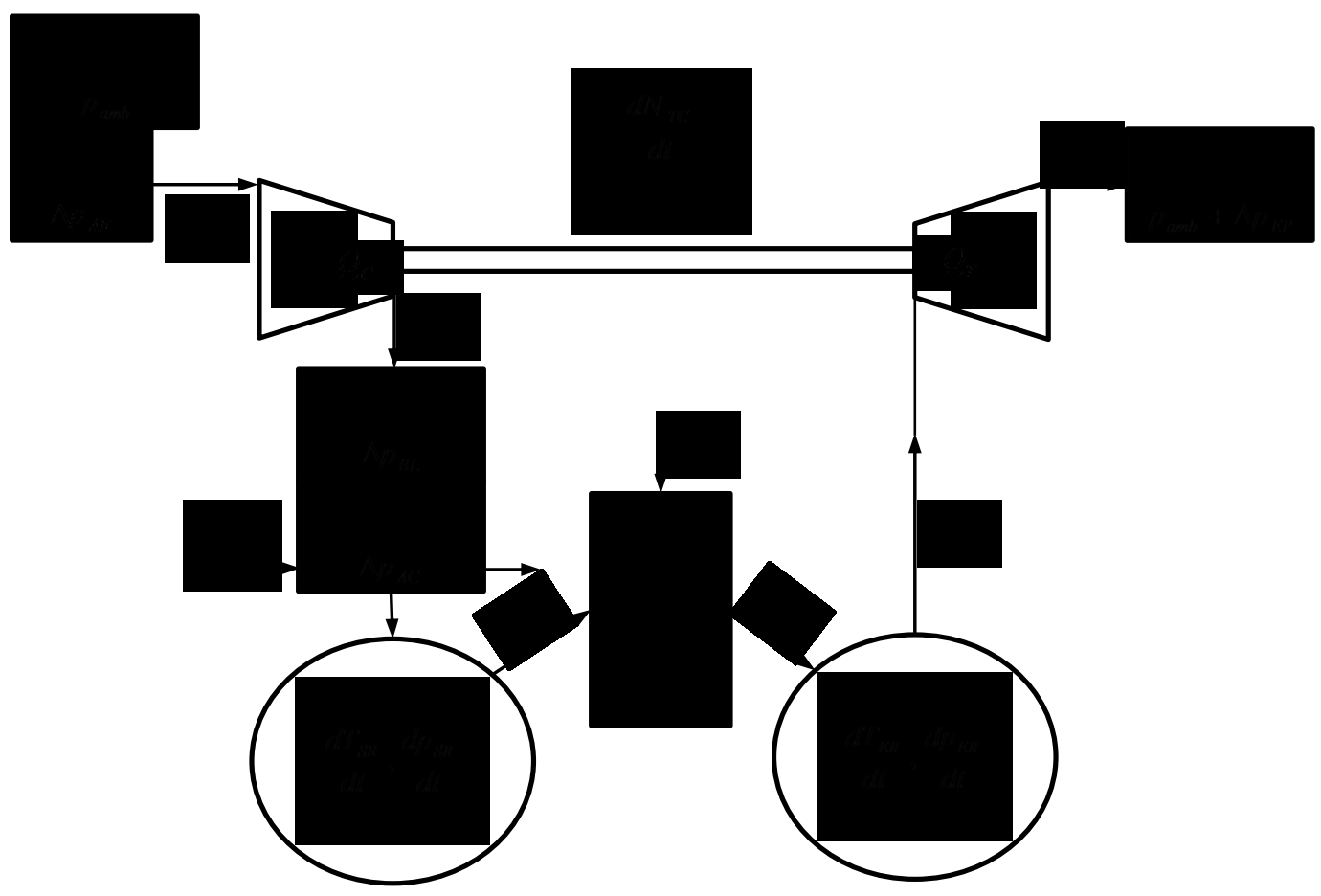

Figure 2. MVEM approach flowchart.

\subsection{Compressor performance map extension model description}

During the ship acceleration manoeuvre, the engine runs in a wide range of speeds and pressure ratios. In order to overcome the limited performance range which is available in turbocharger experimental maps and data, detailed simulation methods are adopted in marine Diesel engine simulation models and diagnostic studies (Sakellaridis et al., 2015). An extended compressor map has been applied in a mean value engine model (Guan et al., 2014), allowing the simulation of the engine transient response in the load region below $50 \%$ of MCR power. However, the last method requires the division of the existing compressor map into zones and the calculation of a set of parameters for each partition, increasing the complexity and the risk of discontinuities during pressure ratio estimation. After the test of various suitable methods, an alternative approach was adopted in this study for the extension of the compressor map and the estimation of its compressor pressure ratio and volumetric flow rate.

The extended compressor model includes the normalization of the available compressor map with the compressor non-dimensional flow and isentropic head coefficients, $\varphi$ and $\Psi$, respectively, which are defined by the following equations: 
$\varphi=\frac{\dot{\mathrm{V}}_{\mathrm{C}}}{\mathrm{A}_{\mathrm{C}} \mathrm{U}_{\mathrm{C}}}$

$\Psi=\frac{\operatorname{pr}_{\mathrm{C}}^{\frac{\gamma_{\mathrm{a}}-1}{\gamma_{\mathrm{a}}}-1}}{\left(\gamma_{\mathrm{a}}-1\right) \mathrm{M}_{\mathrm{im}}^{2}}$

where $U_{C}$ is the compressor impeller tip velocity and $\mathrm{M}_{\mathrm{im}}$ is the compressor impeller tip Mach number, defined as follows:

$\mathrm{U}_{\mathrm{C}}=\pi \mathrm{N}_{\mathrm{TC}} \mathrm{D}_{\mathrm{C} \text {, tip }}$

$\mathrm{M}_{\mathrm{im}}=\frac{\mathrm{U}_{\mathrm{C}}}{\sqrt{\gamma \mathrm{R}_{\mathrm{a}} \mathrm{T}_{\mathrm{amb}}}}$

Justified by numerical and experimental results, (Moore and Greitzer, 1985) suggested a single cubic polynomial equation to describe the compressor map. This approach has been successfully followed in many studies (Eriksson, 2007; Meuleman et al, 1998; Willems, 2000; van Helvoirt, 2007):

$\Psi(\varphi)=\Psi\left(0, \mathrm{M}_{\mathrm{im}}\right)+\mathrm{k}_{\mathrm{GM}, 1}\left(\mathrm{M}_{\mathrm{im}}\right)\left[1+\frac{3}{2}\left(\frac{\varphi}{\mathrm{k}_{\mathrm{GM}, 2}\left(\mathrm{M}_{\mathrm{im}}\right)}-1\right)-\frac{1}{2}\left(\frac{\varphi}{\mathrm{k}_{\mathrm{GM}, 2}\left(\mathrm{M}_{\mathrm{im}}\right)}-1\right)^{3}\right]$

The parameters $\Psi\left(0, \mathrm{M}_{\mathrm{im}}\right), \mathrm{k}_{\mathrm{GM}}, 1\left(\mathrm{M}_{\mathrm{im}}\right)$ and $\mathrm{k}_{\mathrm{GM}},{ }_{2}\left(\mathrm{M}_{\mathrm{im}}\right)$ can be determined from the steady-state compressor map and subsequently interpolated by Polynomials as function of $\mathrm{M}_{\mathrm{im}}$ (Willems, 2000; van Helvoirt, 2007). Thus, the non-dimensional, isentropic head coefficient is calculated as a function of the non-dimensional flow coefficient and the Mach number for the entire operational range of the compressor. Based on the head coefficient, the pressure ratio at the given speed and volumetric flow rate is estimated by using Equation (14).

The Greitzer-Moore's method provides a continuous function for the description of the compressor map. Consequently, this method predicts the compressor operational point when the compressor operates near or beyond the compressor map limits. Moreover, the calculation of method's parameters as polynomial function of Mach number gives the advantage to the model to identify the compressor operational point even when the turbocharger speed is lower than the minimum speed given on the map.

When the non-dimensional parameters $\varphi, \Psi$ have been obtained according to the Greitzer-Moore's method, the compressor isentropic efficiency at low turbocharger speed is calculated based on the non-dimensional torque coefficient and according to the method that is described in (Guan et al., 
2014). Following this study, the proposed normalization of the computed isentropic equation according to the available details is adopted in order to fix the variations in the isentropic efficiency calculation due to compressibility effects.

\subsection{Propeller model description}

For the estimation of the ship propeller torque and thrust, the non-dimensional torque and thrust coefficients are calculated as a second-order polynomial function of advance speed coefficient (Carlton, 2012). The polynomial constants have been estimated using least square regression analysis of the propeller characteristics data, available by sea trials:

$\mathrm{K}_{\mathrm{i}}=\mathrm{k}_{\mathrm{i} 0}+\mathrm{k}_{\mathrm{i} 1} \mathrm{~J}_{\mathrm{P}}+\mathrm{k}_{\mathrm{i} 1} \mathrm{~J}_{\mathrm{P}}^{2} \quad$ with $\quad \mathrm{J}_{\mathrm{P}}=\frac{60 \mathrm{U}_{\mathrm{A}}}{\mathrm{N}_{\mathrm{P}} \mathrm{D}_{\mathrm{P}}}$

Where $\mathrm{U}_{\mathrm{A}}$ is the speed of advance and $\mathrm{i}=\mathrm{Q}$ or $\mathrm{T}$ corresponds to the propeller torque and thrust respectively:

$\mathrm{Q}_{\mathrm{P}}=\mathrm{K}_{\mathrm{Q}} \rho_{\mathrm{SW}} \mathrm{N}_{\mathrm{P}}^{2} \mathrm{D}_{\mathrm{P}}^{5}, \quad \mathrm{~T}_{\mathrm{P}}=\mathrm{K}_{\mathrm{T}} \rho_{\mathrm{SW}} \mathrm{N}_{\mathrm{P}}^{2} \mathrm{D}_{\mathrm{P}}^{4}$

The propeller inertia consists from the propeller air and entrained water inertia:

$\mathrm{I}_{\mathrm{P}, \text { tot }}=\mathrm{I}_{\mathrm{P}, \text { act }}+\mathrm{I}_{\mathrm{P}, \text { entr }}$

The added inertia due to the entrained water is estimated after experiments or by using semiempirical formulae which calculate the entrained water inertia term as a proportion to the actual propeller inertia (Carlton, 2012). In terms of this study, the propeller air inertia is obtained from the available data whilst the entrained water inertia is calculated with the following formula (Lewis and Auslaender, 1960):

$\mathrm{I}_{\mathrm{P}, \text { entr }}=\frac{0.0042 \rho_{\mathrm{SW}}\left(\frac{\mathrm{P}_{\mathrm{P}}}{\mathrm{D}_{\mathrm{P}}}\right)^{2} \mathrm{D}_{\mathrm{P}}^{5}\left(\mathrm{MWR}_{\mathrm{P}}\right)^{2} \mathrm{Z}_{\mathrm{P}}}{\left[1+\left(\frac{\mathrm{P}_{\mathrm{P}}}{\mathrm{D}_{\mathrm{P}}}\right)^{2}\right]\left(0.3+\mathrm{MWR}_{\mathrm{P}}\right)}$

Considering that the propeller air and entrained water inertia depend only on the geometric data of the propeller, their values remain constant during the ship acceleration simulation. 


\subsection{Propulsion system model description}

In order to simulate the propulsion system performance, the propeller dynamics need to be adequately modelled. Based on the previous studies on the dynamics of submerged vehicle thrusters (Yoerger et al., 1990), a single-state model was developed based on the Reynolds transport theorem (White, 2009), and assuming that the propeller acts as an actuator disk in a thrust tunnel. The control volume that is used for the Reynolds theorem is assumed to be a cylinder with diameter and length equal to the propeller diameter (Figure 3). The fluid is considered incompressible, whilst any friction losses, rotational flow and gravity effects are neglected. Further development of this model includes the influence of the tunnel entrained fluid mass (McLean, 1991).

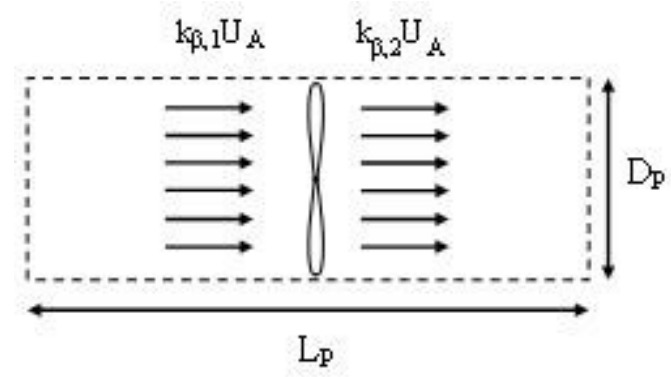

Figure 3. Control volume of propeller as actuator disk.

Based on this model, the available thrust of the propeller is described by the following formula:

$$
\mathrm{T}_{\mathrm{P}}=\rho_{\mathrm{SW}} \mathrm{L}_{\mathrm{P}}\left(1+\mathrm{K}_{\alpha}\right) \ddot{\mathrm{V}}_{\mathrm{P}}(\mathrm{t})+\frac{\rho_{\mathrm{SW}} \Delta \mathrm{k}_{\beta}}{\mathrm{A}_{\mathrm{P}}} \dot{\mathrm{V}}_{\mathrm{P}}(\mathrm{t})\left|\dot{\mathrm{V}}_{\mathrm{P}}(\mathrm{t})\right|
$$

where $K_{\alpha}$ is the percentage of the entrained water mass in the control volume, $\mathrm{k}_{\beta}$ is the dimensionless momentum flux correction factor of the flow $\left(k_{\beta, 1}\right.$ and $k_{\beta, 2}$ for upstream and downstream flow respectively), and $\dot{V}_{\mathrm{P}}(\mathrm{t})$ is the volumetric flow rate of sea water that passes through the propeller:

$\dot{\mathrm{V}}_{\mathrm{P}}(\mathrm{t})=\mathrm{A}_{\mathrm{P}} \mathrm{U}_{\mathrm{A}}$

The first term of thrust force in Equation (22) describes the unsteady flow within the control volume, whilst the second term describes the produced force due to the actuator disk (propeller). The first term can be modified to the following:

$\mathrm{m}_{\mathrm{SW}} \ddot{\mathrm{V}}_{\mathrm{P}}(\mathrm{t})=\rho_{\mathrm{SW}} \mathrm{L}_{\mathrm{P}}\left(1+\mathrm{K}_{\alpha}\right) \ddot{\mathrm{V}}_{\mathrm{P}}(\mathrm{t})$ 
where $\mathrm{m}_{\mathrm{Sw}}$ includes the fluid mass of the control volume and the added water mass that is entrained in the control volume, estimated by Schwanecke's theory in Equation (26) (Carlton, 2012):

$\mathrm{m}_{\mathrm{SW}}=\rho_{\mathrm{SW}} \frac{\pi \mathrm{D}_{\mathrm{P}}^{2}}{4} \mathrm{D}_{\mathrm{P}}+\mathrm{m}_{\mathrm{SW}, \text { entr }}$

$\mathrm{m}_{\mathrm{SW}, \text { entr }}=0.2812 \frac{\pi \rho_{\mathrm{SW}} \mathrm{D}_{\mathrm{P}}^{3}}{\mathrm{Z}}\left(\frac{\mathrm{A}_{\mathrm{eff}}}{\mathrm{A}_{\mathrm{P}}}\right)^{2}$

The dimensionless flux correction factor $\mathrm{k}_{\beta}$ in the second term of Equation (22) describes the disturbance of the fluid flow and it depends on the flow profile before and after the actuator disk. The estimation of this parameter is crucial for the successful simulation of the propeller performance (White, 2009). In this work, the dimensionless momentum flux factor is predicted by using a polynomial regression formula as a function of propeller speed:

$\Delta \mathrm{k}_{\beta}=\mathrm{k}_{\mathrm{k} \beta, 1}+\mathrm{k}_{\mathrm{k} \beta, 2} \mathrm{~N}_{\mathrm{P}}$

The results of the regression formula have been validated against the wake fraction coefficient from ship trials for navigation at constant speed and in calm sea water conditions. Due to lack of trials data in transient conditions, the effect of sea state to the fluid flow profile is neglected, assuming that the dimensionless momentum flux factor depends only on the ship speed.

Replacing the Equations (23) and (24) in the Equation (22), the differential formula for the calculation of speed of advance is derived to the following one:

$\frac{\mathrm{dU}_{\mathrm{A}}}{\mathrm{dt}}=\frac{\mathrm{T}_{\mathrm{P}}}{\mathrm{m}_{\mathrm{SW}}}-\frac{\rho_{\mathrm{SW}} \mathrm{A}_{\mathrm{P}} \Delta \mathrm{k}_{\beta}}{\mathrm{m}_{\mathrm{SW}}} \mathrm{U}_{\mathrm{A}}\left|\mathrm{U}_{\mathrm{A}}\right|$

where the propeller thrust is estimated with Equation (19).

The vessel speed, $U_{s}$, is calculated through the dynamic equations of ship motions. Considering that the acceleration of the ship is investigated only in head sea direction and the sea conditions vary from calm water till a high sea state, only the longitudinal motion equation is used, assuming that the forces in the other directions are neglected:

$\left(\mathrm{m}_{\mathrm{S}}+\mathrm{m}_{\text {hydro }}\right) \frac{\mathrm{dU}_{\mathrm{S}}}{\mathrm{dt}}=(1-\mathrm{t}) \mathrm{T}_{\mathrm{P}}-\mathrm{RR}_{\mathrm{S}, \text { tot }}$

The ship mass in the Equation (29) consists from the sea water displacement mass, which is calculated by the sea water density, the hull displaced volume in full load condition, and the added hydrodynamic mass due to surge motion. The surge hydrodynamic added mass is estimated 
empirically as a proportion of the ship total mass by following the Sargent and Kaplan method (Journée, 2001; Sargent and Kaplan, 1974). The proportional coefficient depends on the vessel main dimensions.

The total resistance of the ship consists from the calm water resistance, the added resistance due to waves and the resistance due to wind:

$\mathrm{RR}_{\mathrm{S}, \mathrm{tot}}=\mathrm{RR}_{\mathrm{S}, \mathrm{CW}}+\mathrm{RR}_{\mathrm{S}, \mathrm{AWV}}+\mathrm{RR}_{\mathrm{S}, \mathrm{AWI}}$

The calm water resistance is expressed as a polynomial function of vessel speed based on the ship's sea trials:

$\mathrm{RR}_{\mathrm{S}, \mathrm{CW}}=\mathrm{k}_{\mathrm{RR}, 2} \mathrm{U}_{\mathrm{S}}^{2}+\mathrm{k}_{\mathrm{RR}, 1} \mathrm{U}_{\mathrm{S}} \mathrm{k}_{\mathrm{RR}, 0}$

where constants $k_{R R, 0}, k_{R R, 1}$ and $k_{R R, 2}$ are estimated according to the vessel's resistance curve.

The other terms of Equation (30) correspond to the case of sailing in head seas. The added wave resistance $\left(\mathrm{RR}_{\mathrm{S}}, \mathrm{AWV}\right)$ is estimated with the STAWAVE-2 model that was developed by STA-JIP to approximate the mean increase on the resistance due to heading in regular waves (van den Boom et al., 2013). The method is used from (ITTC, 2014; IMO, 2013) for the correction of total resistance during the assessment of vessel's power performance.

This method is the result of experimental data collected from various ships under different wave characteristics The required input for the estimation of added resistance includes the main particulars of the ship (e.g. length, draught), the wave characteristics (e.g. amplitude, length, frequency) and the Froude number. STAWAVE-2 method was selected instead of an analytical method due to the limited data which are required as input, and taking into account that the simulation is investigated in head sea waves.

Finally, the added resistance induced by wind $\left(R_{\mathrm{S}, \mathrm{AWI}}\right)$ is accounted by using a physicalcomponent-method, developed by (Fujiwara et. al., 2006). The wind resistance is calculated as a function of the relative wind angle, vessel's main dimensions and the exposed areas above the waterline in the lateral and transverse direction. In this method, the wind angle and the relative direction and speed between vessel and wind are taken into account, correcting the final estimation of the wind added resistance. However, the resistance increase due to other parameters such as hull 
roughness or trim conditions is neglected, focusing only to the vessel acceleration at clean hull and laden conditions at various sea states.

Using Equations (28) and (29), the model calculates the advance and vessel speed respectively on each time step. Then, the wake fraction is estimated by the following formula:

$\mathrm{W}=\frac{\mathrm{U}_{\mathrm{S}}-\mathrm{U}_{\mathrm{A}}}{\mathrm{U}_{\mathrm{S}}}$

Considering that the wake profile of the propeller varies with time, the thrust deduction coefficient is modified as well. The interconnection of the thrust deduction and wake fraction coefficients is given in Equation (33), utilizing the propeller thrust loading coefficient (Tsakonas, 1958):

$\mathrm{t}=2\left[\frac{-1+\frac{1+\mathrm{k}_{\mathrm{T}, \text { load }}}{2}}{\mathrm{k}_{\mathrm{T}, \text { load }}}\right] \frac{\mathrm{w}}{1-\mathrm{w}}$

where the thrust loading coefficient $\mathrm{k}_{\mathrm{T} \text {, load }}$ is given by the following formula:

$\mathrm{k}_{\mathrm{T}, \text { load }}=\frac{\mathrm{T}_{\mathrm{P}}}{\frac{1}{2} \rho_{\mathrm{SW}} \mathrm{U}_{\mathrm{A}}^{2} \mathrm{~A}_{\mathrm{P}}}$

Based on the wake fraction and the thrust deduction coefficient, the ratio of effective power to thrust power, defined as hull efficiency, is calculated as follows:

$\eta_{H}=\frac{1-\mathrm{t}}{1-\mathrm{w}}$

The shafting system efficiency, $\eta_{\mathrm{Sh}}$, is considered to be as a function of engine power (SNAME, 1975), whilst the overall propulsive efficiency is defined according to the following equation (Carlton, 2012):

$\eta_{\mathrm{D}}=\frac{\pi \mathrm{N}_{\mathrm{P}} \mathrm{Q}_{\mathrm{P}}}{30 \mathrm{P}_{\mathrm{B}}}=\eta_{\mathrm{H}} \eta_{\mathrm{R}} \eta_{\mathrm{P}} \eta_{\mathrm{sh}}$

\subsection{Sea state model description}

For the estimation of the added wave and wind resistance in adverse sea conditions, the wind speed and the wave profiles have to be identified. For the selection of wave profile, various models have been proposed based on the description of the wave spectra (ITTC, 2002).

In this study, a simple wave spectrum is used for the sea state modelling, as proposed by (Pierson and Moskowitz, 1963). This is valid only on fully developed seas, where the waves are into 
equilibrium with the wind. According to this model, the wind speed at the height of $19 \mathrm{~m}$ is required as input to obtain the spectrum form constants $\mathrm{k}_{\mathrm{A}, \mathrm{PM}}$ and $\mathrm{k}_{\mathrm{B}, \mathrm{PM}}$ :

$S(f)=\frac{k_{A, P M}}{f^{5}} \exp \left(-\frac{k_{B, P M}}{f^{4}}\right)$

Alternative spectra, such as JONSWAP (Hasselmann et al., 1973), take into account additional parameters for a better approximation of experimental data, such as the location and the shape of wave (fetch length and shaper parameters, respectively). Setting as a target the development of a simplified model that will use only limited input data for the estimation of the wave profile and due to the lack of experimental data, the Pierson-Moskowitz's model is adopted herein. Considering that STAWAVE-2 method is used for the estimation of added wave resistance in regular head waves, the significant wave amplitude and the mean wave frequency of Pierson-Moskowitz's model have been selected for the description of wave profile in each wind speed, as provided by the following equations (Pierson and Moskowitz, 1963):

$H_{\mathrm{wV}}=\sqrt{\frac{\mathrm{k}_{\mathrm{A}, \mathrm{PM}}}{\mathrm{k}_{\mathrm{B}, \mathrm{PM}}}}$

$\overline{\mathrm{f}}_{\mathrm{wv}}=1.2254 \mathrm{k}_{\mathrm{B}, \mathrm{PM}}^{1 / 4}$

where $\mathrm{k}_{\mathrm{A}, \mathrm{PM}}$ and $\mathrm{k}_{\mathrm{B}, \mathrm{PM}}$ are the spectrum form constants of Pierson-Moskowitz's model. Based on these wave characteristics and assuming that ship sails in deep water, the wave length is calculated, describing the wave profile that is applied on the ship. Thus, the added resistance due to the selected wave is estimated according to the STAWAVE-2 method.

\subsection{Model structure}

The propulsion system performance simulator flowchart is depicted in Figure 4. The simulator requires the ordered engine speed and the wind speed as input. Moreover, the initial conditions (engine, vessel and turbocharger speed, scavenging and exhaust gas receiver pressure and temperature) for the utilized differential equations of the simulator have to be set according to the desired vessel speed at the start of the simulation.

The ordered engine speed is used by the PI control unit of the engine governor to identify the rack position, which defines the fuel flow rate in each time step. Taking into account the vessel speed and 
the sea state condition, the simulator calculates the total resistance on the hull. Simultaneously, based on the speed of engine and the gear ratio, the simulator calculates the thrust and torque from the propeller.

The engine speed variation is calculated according to Equation (11), taking into account the engine and propeller torque. The propeller thrust is used for the calculation of the advance speed variation (Equation 28) and the vessel speed (Equation 29). Due to the large inertia of the hull, the engine response is expected to be quicker than the hull. As a result, a 'virtual' accelerator factor $\left(\mathrm{c}_{\mathrm{acc}}\right)$ is adopted in Equation (29). This factor is used only when the ordered engine speed has been achieved whilst the ship is still accelerating, reducing the computational cost of the simulation for the estimation of the vessel final speed. The simulation stops only when the maximum speed of the vessel has been achieved for the given sea state. The impact of the 'virtual' acceleration factor to the results accuracy is negligible but reduces the computational cost for the simulation significantly. In this work, the acceleration factor has been set equal to $c_{a c c}=300$, reducing the computational time $94 \%$ in comparison with the simulation performance without the factor application.

In order to capture the dynamics of the overall system the trapezoidal rule has been selected as an implicit second order method for the solution of the first order ordinary differentials. This method provides adequate accuracy and low computational cost for the fast evaluation of the ship transient performance. 


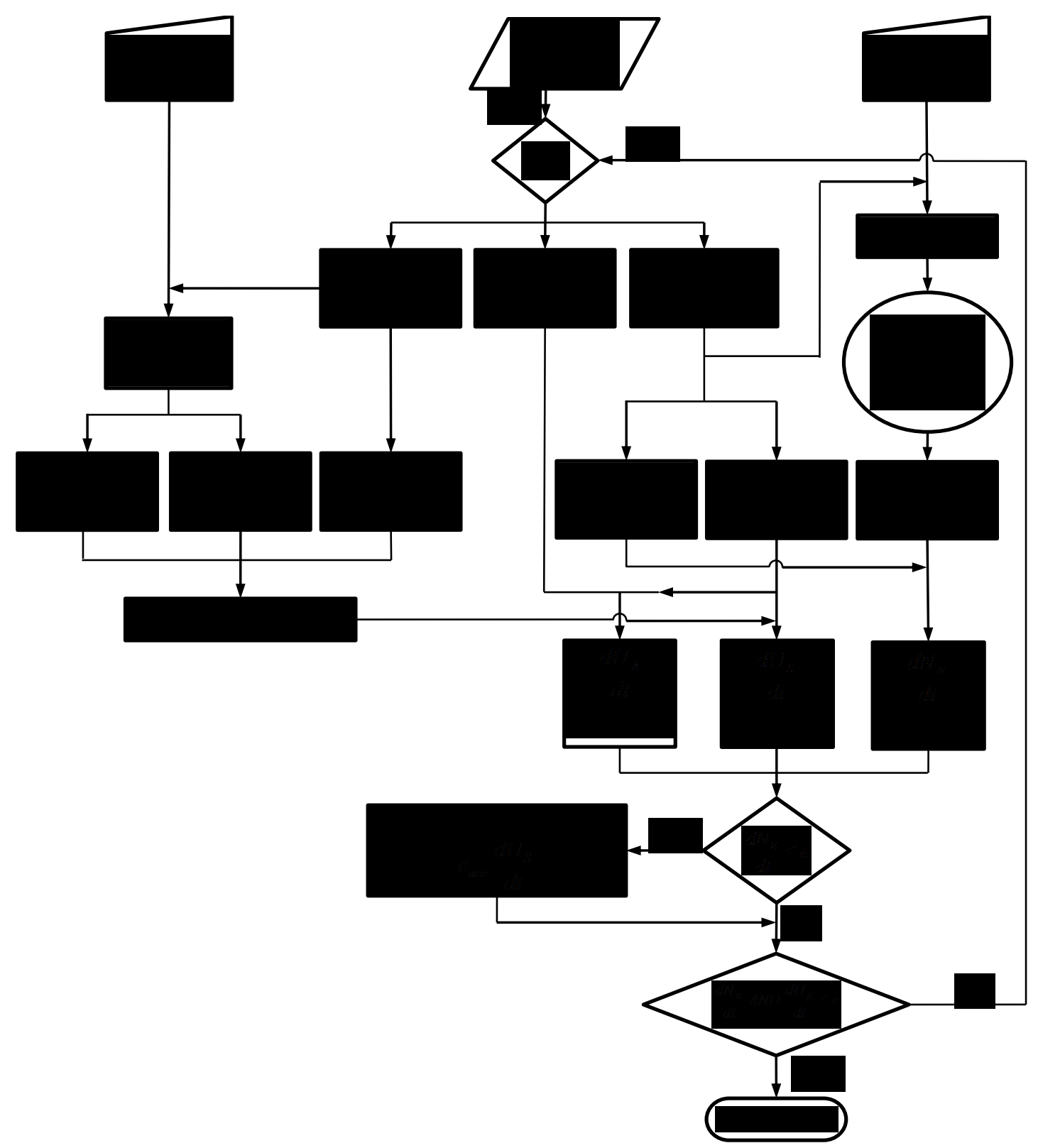

Figure 4. Flowchart of Propulsion System Performance Simulator 


\section{$4 \quad$ Results and Discussions}

\subsection{Propulsion system model set up}

The developed model has been used for the estimation of an Aframax crude oil tanker vessel propulsion system performance and acceleration in various sea state conditions. The vessel is powered by a two-stroke, turbocharged, marine Diesel engine. Additionally, an air cooler unit is installed between the compressor and the inlet receiver. An electrically driven blower is used to provide the required air flow at low engine loads. The main propulsion engine is connected directly to a fixed pitch four-blade propeller. The main particulars of the ship, the main engine characteristics as provided by the engine manufacturer (MAN B\&W, 2015), as well as the propeller parameters are summarized in Table 1.

Table 1. Vessel and propulsion system parameters.

\begin{tabular}{|l|r|l|}
\hline Ship parameters & \multicolumn{2}{|r|}{ Crude oil tanker } \\
\hline Type & 115000 & MT \\
\hline Size & 250 & $\mathrm{~m}$ \\
\hline Length overall & 44 & $\mathrm{~m}$ \\
\hline Breadth & 15 & $\mathrm{~m}$ \\
\hline Draught & 135000 & $\mathrm{MT}$ \\
\hline Displacement & & \\
\hline Propulsion engine parametrs & MAN 7S60MC-C \\
\hline Engine type & 7 & \\
\hline Number of cylinders & 600 & $\mathrm{~mm}$ \\
\hline Bore & 2292 & $\mathrm{~mm}$ \\
\hline Stroke & 14300 & $\mathrm{~kW}$ \\
\hline Brake power (MCR) & 110 & $\mathrm{r} / \mathrm{min}$ \\
\hline Engine speed (MCR) & 18 & $\mathrm{bar}$ \\
\hline BMEP (MCR) & & \\
\hline
\end{tabular}




\begin{tabular}{|l|r|l|}
\hline Propeller parameters & \multicolumn{2}{|c|}{ Fixed pitch } \\
\hline Type & 7.5 & $\mathrm{~m}$ \\
\hline Diameter & 4 & - \\
\hline Number of blades & 0.66 & - \\
\hline $\begin{array}{l}\text { Pitch over Diameter } \\
\text { ratio }\end{array}$ & 0.52 & - \\
\hline Area ratio & \\
\hline
\end{tabular}

In order to set up the model for the investigated ship, the main particulars of the engine, the geometric data of propeller and engine, as well as the performance curves of air blower, air cooler and turbocharger have been used as input by the model. The default value of the speed slope limiter applied on the governor has been obtained from the manufacturer engine load acceptance diagram (MAN B\&W, 2015), given in Table 2.

Table 2. Engine speed acceleration/deceleration slopes.

\begin{tabular}{|l|c|c|}
\hline & $\begin{array}{l}\text { Acceleration engine speed } \\
\text { slope }(\mathrm{r} / \mathrm{min} / \mathrm{s})\end{array}$ & $\begin{array}{l}\text { Deceleration engine } \\
\text { speed slope }(\mathrm{r} / \mathrm{min} / \mathrm{s})\end{array}$ \\
\hline Engine speed $<58 \mathrm{r} / \mathrm{min}$ & 0.015 & 0.03 \\
\hline Engine speed $\geq 58 \mathrm{r} / \mathrm{min}$ & 0.04 & 0.08 \\
\hline
\end{tabular}

The lower heating value of the fuel used for the simulation was set to $42.7 \mathrm{MJ} / \mathrm{kg}$. The developed engine model has been validated against the engine shop trials data, whilst the overall propulsion system simulator has been validated for calm water operation at steady state conditions against the ship trials results. During the propulsion system validation process, the propeller wake profile was setup through a trial-error method. 


\subsection{Validation process}

The performance of the engine model simulator was tested for a load range from $25 \%$ to $100 \%$ of the maximum continuous rating (MCR) point, and validated based on the available data from the engine shop trials. During the engine simulator validation process, only the engine model was used by setting as input the rack position and the engine crankshaft speed that were indicated from the measurements, neglecting the impact of propeller's torque to the engine.
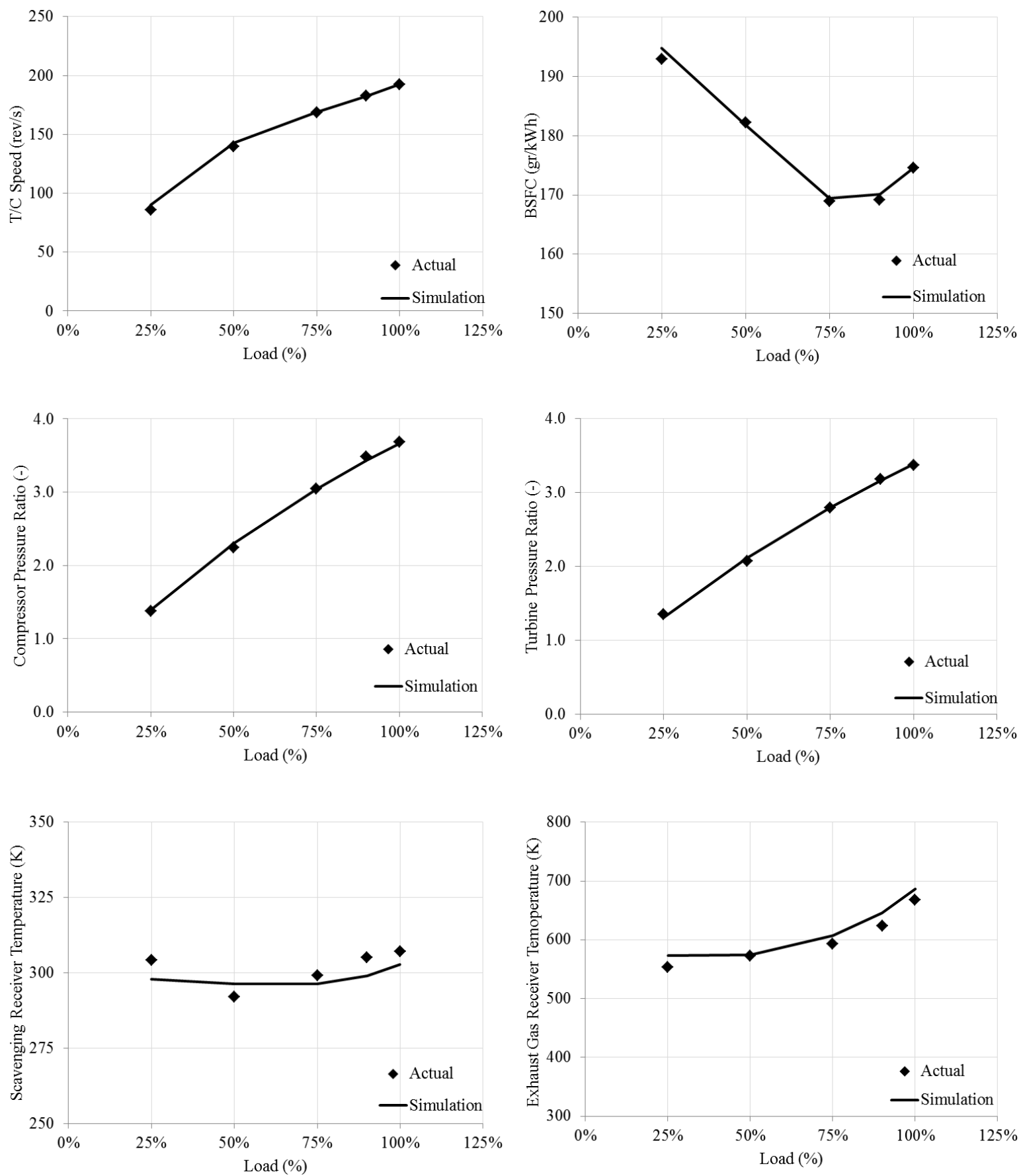

Figure 5. Comparison of simulation results with shop trials data at various engine performance loads. 
The deviation between the engine model results and the recorded performance is presented in Figure 5. During the validation process, the maximum error of $6 \%$ was observed during the prediction of exhaust gas temperature aft the turbine outlet, at $25 \%$ load of MCR. The best accuracy of engine model results is obtained at the load range from $75 \%$ to $100 \%$ of engine MCR, where a minimum of error it was observed. Even though the error increases in lower loads, the engine model predicts with adequate accuracy the engine performance parameters.

In addition to the engine performance validation process, the simulator was validated for the ship hydrodynamic performance prediction accuracy. In this case, the simulator was tested and compared with the available results from sea trials. The trial test was performed in calm sea state (wind speed equal to zero), and the ordered engine speed was constant for each trial run. The error between the simulation results and the sea trials parameters elaborated according to (ISO, 2015) is depicted in Table 3.

Based on the provided results, a maximum error of around $1 \%$ is observed for the prediction of the vessel total resistance at $50 \%$ of MCR. Therefore, it can be inferred that this model predicts satisfactorily the hydrodynamic performance of propeller. However, the validation process was performed only for the steady state conditions of the ship in calm water sea state, whilst the dimensionless flux correction factor of Equation (27) has been estimated through a trial-error method. Table 3. Percentage error of the predicted parameters against ship trials

\begin{tabular}{|l|l|c|c|c|c|}
\hline Engine load & $\%$ & 50 & 75 & 90 & 100 \\
\hline Vessel speed & $\%$ & -0.32 & 0.43 & -0.38 & -0.22 \\
\hline Speed of advance & $\%$ & -0.34 & -0.24 & -0.31 & -0.15 \\
\hline Total resistance & $\%$ & 1.07 & 0.52 & 0.42 & 0.06 \\
\hline Engine break power & $\%$ & 0.14 & 0.28 & 0.45 & 0.32 \\
\hline
\end{tabular}

Due to lack of propulsion system performance data in adverse sea conditions, the estimated dimensionless flux correction factor in calm water conditions has been applied also for the simulation in rough sea conditions. Moreover, the impact of engine acceleration on the shafting system torsional 
vibrations and structural strength was not taken into consideration during simulation, focusing on the effect of fuel governor control system and engine limiters to the propulsion system performance.

\subsection{Acceleration in adverse sea states}

The developed model has been used for the assessment of ship propulsion performance during acceleration in various sea conditions. The investigated sea states are presented in Table 4, including the wind speed that was defined manually in correlation with the selected sea state (WMO, 1970) and the estimated wave profile according to the Pierson-Moskowitz's sea state model (Pierson and Moskowitz, 1963). High sea state was selected as the worst case scenario for the investigation of ship acceleration, limiting the effects of heave and pitch forces to the longitudinal motion of ship. Moreover, the produced wave profile on this sea state allows a steady flow at the propeller, based on the fully propeller emergence $\left(\mathrm{H}_{\mathrm{Wv}} / \mathrm{D}_{\mathrm{P}}>0.65\right)$ (Minsaas et al., 1983).

Table 4. Sea state parameters and maximum vessel speed.

\begin{tabular}{|l|c|c|c|c|}
\hline Sea state & Wind speed $(\mathrm{m} / \mathrm{s})$ & Wave frequency $\left(\mathrm{s}^{-1}\right)$ & Wave height $(\mathrm{m})$ & Wave length $(\mathrm{m})$ \\
\hline Calm & 0 & - & 0 & - \\
\hline Slight & 7.45 & 0.232 & 1.25 & 28.99 \\
\hline Moderate & 10.55 & 0.164 & 2.50 & 58.13 \\
\hline Rough & 13.35 & 0.130 & 4.00 & 93.09 \\
\hline High & 18.90 & 0.092 & 8.02 & 186.57 \\
\hline
\end{tabular}

Considering that the main objective of this study is to estimate the acceleration of the ship under different sea state conditions, the simulation was performed for the acceleration from a constant vessel speed to the maximum speed that could be achieved within the selected sea state. In this respect, the vessel speed of 5 knots was selected as initial condition, taking into account that this speed provides adequate manoeuvrability to the ship under any sea state. The simulation stops when the engine performs at the maximum available load for the operating engine speed and the vessel sails at the maximum available speed.

In order to simulate this acceleration, the ship is assumed to be sailing at the initial speed and at the $30^{\text {th }}$ second, the maximum ordered engine speed is applied to the governor $(110 \mathrm{r} / \mathrm{min})$ resulting in an 
increase of the engine load, confined by the engine speed slope limiter. The acceleration is considered to be continuous, without any pauses during the engine load increase, thus simulating the ship acceleration in emergency conditions. The initial conditions of the differential equations system for the propulsion system simulator (vessel, engine and turbocharger speed, exhaust gas and scavenging receiver pressure and temperature) were selected by error minimization process, in order to obtain the initial speed of 5 knots for the given sea state in steady conditions.

Figure 6 provides the time variations of the total resistance, the vessel speed, the propulsive efficiency, the engine crankshaft speed, the turbocharger speed, the engine load percentage, the exhaust gas receiver temperature and the air mass flow rate during the simulation in the investigated sea states.

The effect of engine speed slope limiter incorporated in the engine control unit is shown on the engine performance. At low engine speeds, the low engine speed slope is activated from the PI controller, leading to a slow increase of the engine and turbocharger speed, as well as the engine load. Due to the engine low load operation, the air mass flow rate remains at low levels as well. On the other hand, when the engine crankshaft speed increases over the $58 \mathrm{r} / \mathrm{min}$ the higher engine speed slope limiter is activated. Thus, the governor control unit permits faster increase of the fuel mass flow rate to the engine which results in a quicker increase of the engine speed.

The variation of engine speed slope limiter affects the temperature of the exhaust gas receiver as it is shown in Figure 6. When the fuel mass flow rate increases, the air-fuel ratio reduces due to the turbocharging system inertia and as a consequence, the exhaust gas receiver temperature increases abruptly, indicating high engine thermal loading. The increase of the exhaust gas energy tends to increase the turbine produced power, increasing the turbocharger speed and the compressor pressure ratios. This results in an increase of the air mass flow rate and consequently the exhaust gas mass flow rate. After some time, and while the engine is operating under the same engine speed slope limiter, the balance in the exhaust gas receiver is restored, stabilizing the exhaust gas temperature, the turbocharger speed and the air mass flow rate. 

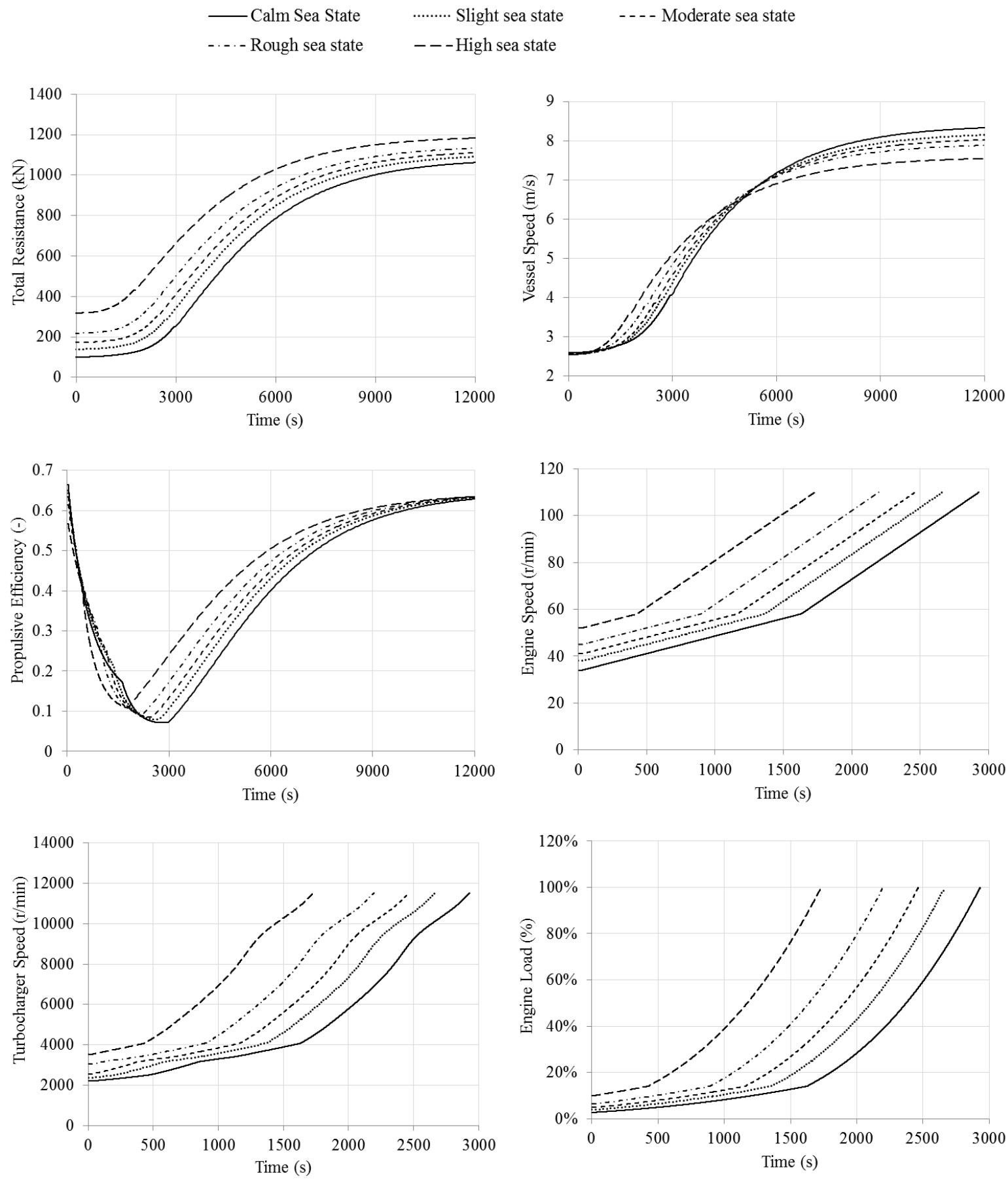

Figure 6. Simulation results at various sea states.

In case of harsher sea states, the ship resistance increases as it was expected, modifying the propulsion system initial conditions which are required for the same initial vessel speed assumption. Thus, the initial conditions for each investigated sea state vary. However, even if the initial conditions are different, the acceleration rate of the engine is identical. 
As it is shown in Figure 6, the vessel acceleration consists of three different phases. The first phase includes the slow acceleration of the engine due to the imposed engine speed slope limiter. The second phase includes the faster acceleration of the engine because of the engine speed slope limiter, whilst the third phase includes the engine operation at its maximum engine load. In the first two stages, the vessel acceleration is slow, whilst on the third phase the vessel acceleration rate increases and the ship obtains its maximum speed.

a)

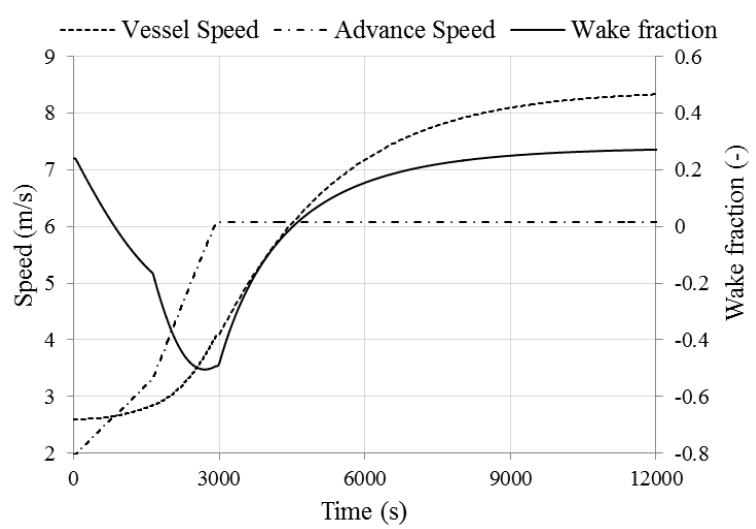

b)

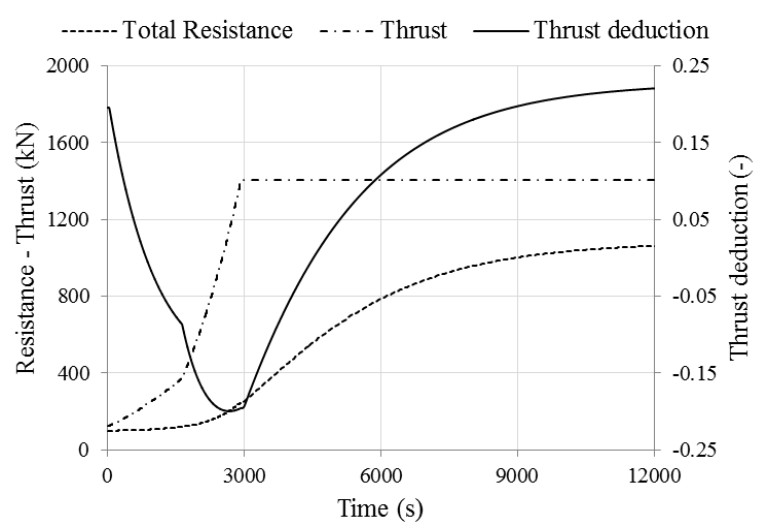

Figure 7. Time variations of a) wake fraction factor, vessel speed and advance speed, and b) thrust deduction factor, resistance and thrust in calm water.

The propeller wake profile varies during the vessel acceleration. Figure 7a shows the variation of the wake fraction factor when the ship accelerates in calm water conditions. The reduction of the wake fraction factor, observed till the $2800^{\text {th }}$ second, is attributed to the difference between the acceleration rates of propeller and vessel flow speeds. The faster acceleration of the propeller rotational speed (as shown in Figure 6) reduces the ship wake fraction due to the difference between the flow speed at the propeller inlet and the actual vessel speed. The minimum wake fraction is calculated at the around $2800^{\text {th }}$ second when the propeller speed achieves its maximum value whilst the vessel speed is still low. After this moment and in conjunction with the maximum propeller speed maintained from the engine, the vessel speed increases faster. Therefore, the increased vessel speed and the constant propeller speed increase the wake fraction. 
Similarly to the wake fraction factor, the thrust deduction factor is affected by the propeller hydrodynamic performance as shown in Figure $7 \mathrm{~b}$. Due to the propeller fast acceleration the thrust is greater than the hull resistance, decreasing the thrust deduction factor till the $2800^{\text {th }}$ second. This difference between thrust and resistance forces leads to the ship acceleration when the maximum load and speed is maintained from the engine. When the balance between the two forces is established, the thrust deduction factor is restored to their final steady state values. The impact of the difference between propeller and vessel acceleration rates is presented also on the hydrodynamic propulsive efficiency in Figure 6.

\subsection{Investigation of simulator performance}

According to the preceding analysis, the variation of wake profile affects the vessel acceleration in various sea states for a given profile of governor limiters. Considering that the acceleration profiles are similar at various sea states, the effect of fuel governor engine speed slope limiter in calm sea state will be further analysed in this section.

In order to investigate the effect of the engine speed slope limiter to the ship hydrodynamic performance, various acceleration rates were tested, in addition to the torque and scavenging air pressure limiters, by using the propulsion system performance simulator as shown in Table 5 . Moreover, an additional case is investigated without the engine speed slope limiter (engine speed slope limiter free case), where only the torque and air scavenging limiters are used in engine control unit.

Table 5. Tested engine speed slope limiters

\begin{tabular}{|c|c|c|}
\hline & Engine speed $<58 \mathrm{r} / \mathrm{min}$ & Engine speed $\geq 58 \mathrm{r} / \mathrm{min}$ \\
\hline Engine speed slope limiter A & $0.015 \mathrm{r} / \mathrm{min} / \mathrm{s}$ & $0.04 \mathrm{r} / \mathrm{min} / \mathrm{s}$ \\
\hline Engine speed slope limiter B & $0.03 \mathrm{r} / \mathrm{min} / \mathrm{s}$ & $0.08 \mathrm{r} / \mathrm{min} / \mathrm{s}$ \\
\hline Engine speed slope limiter C & $0.06 \mathrm{r} / \mathrm{min} / \mathrm{s}$ & $0.20 \mathrm{r} / \mathrm{min} / \mathrm{s}$ \\
\hline Engine speed slope limiter D & $0.15 \mathrm{r} / \mathrm{min} / \mathrm{s}$ & $0.4 \mathrm{r} / \mathrm{min} / \mathrm{s}$ \\
\hline Engine speed slope limiter free & - & - \\
\hline
\end{tabular}


a)

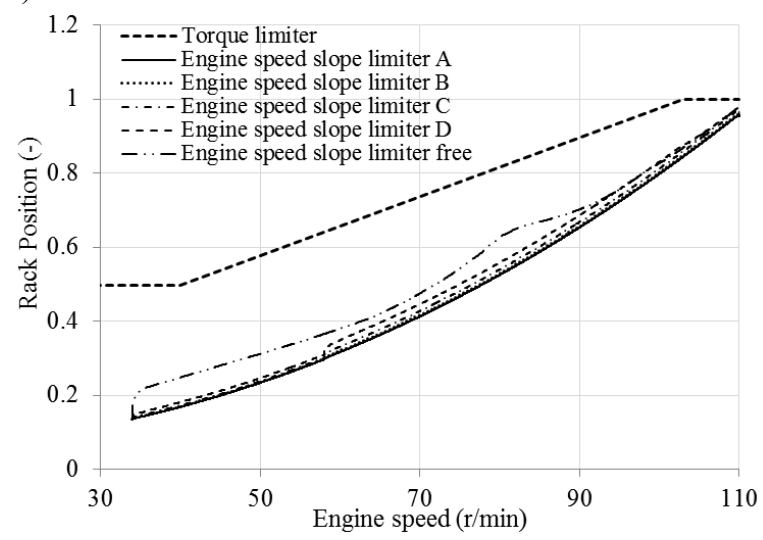

b)

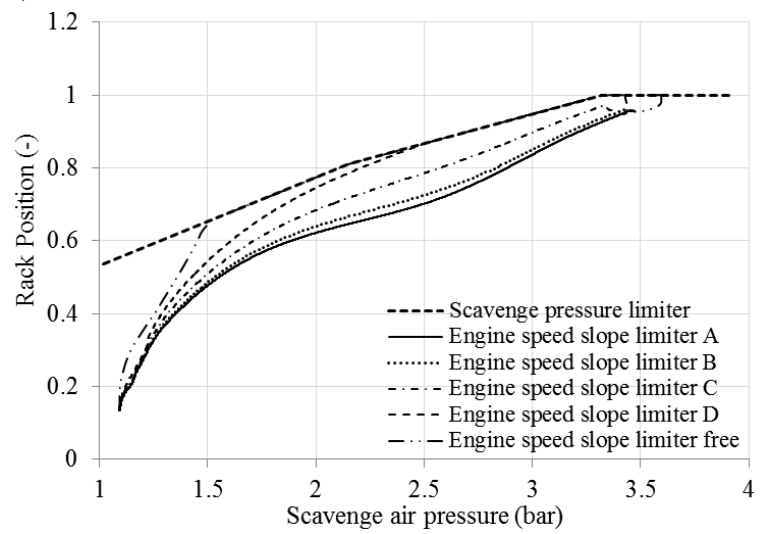

Figure 8. Variations of rack position versus a) engine speed and b) scavenge air receiver pressure.

The sensitivity analysis for the engine speed slope limiters application is performed in calm sea conditions by assuming identical initial conditions and engine ordered speed to the simulator. The rack position variations as function of engine speed and scavenging air receiver pressure are shown in Figure 8 . According to the simulation results, the engine torque and speed limiters are not activated in the case of the slope limiter profile A, which was the same as the one used in the ship trials. In the cases of speed slope limiter profiles B and C, the scavenging air limiter is activated when the engine performs at the maximum load. In the case of profile D, where the speed slope is further increased, the scavenging air limiter is activated at a lower scavenging pressure (2.25 bar) for the protection of the engine. Finally, when the engine speed slope limiter is neglected, the scavenging air limiter is activated from the low engine loads, defining the fuel flow rate to the engine. However, the torque limiter is not activated in any of the investigated cases, apart from the case when the engine operates at its maximum load. 
_- Engine speed slope limiter A

-. - - Engine speed slope limiter C

-..-Engine speed slope limiter free

a)

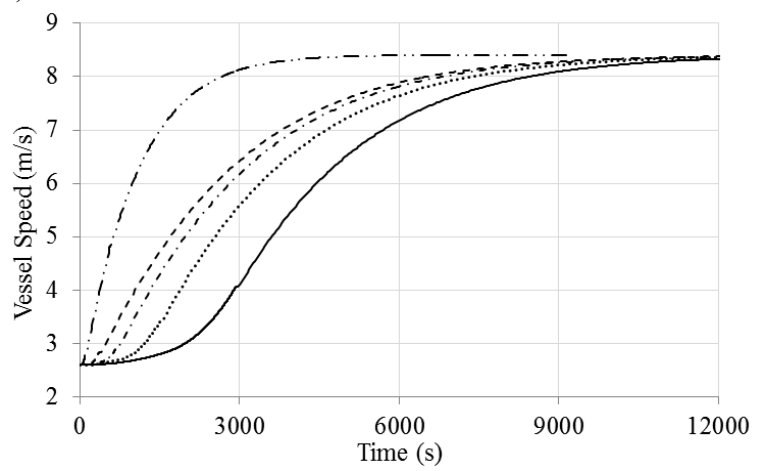

……. Engine speed slope limiter B

- - - - Engine speed slope limiter D

b)

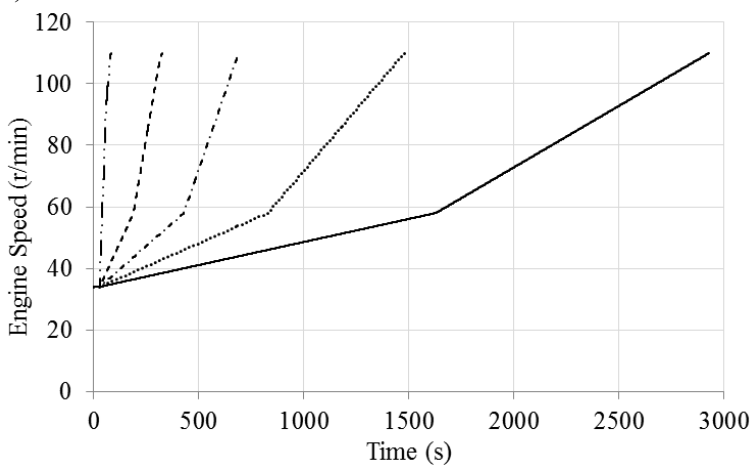

Figure 9. Time variations of a) vessel speed and b) engine speed, for various engine speed slope limiters.

The effect of various engine speed slope limiter profiles in the hydrodynamic performance of the ship can be deduced by analysing the ship speed and engine rotational speed time variations as shown in Figure 9. Increasing slope in speed slope limiters results a faster acceleration of the engine crankshaft speed. Especially in the case that speed slope limiter is neglected, the engine accelerates to its maximum speed within seconds (around $100 \mathrm{~s}$ ). The faster acceleration of engine speed affects the vessel speed, which achieves its maximum speed sooner.

The application of different acceleration slope profiles to the governor control unit affects the performance of the propulsion system components as it is presented in Figure 10. The fuel mass flow rate increases due to the rack position control, leading to greater engine load for the same engine speed. Moreover, the variation of engine speed slope limiter affects also the performance of the turbocharger and the temperature of exhaust gas receiver. The faster engine load increase results in a faster increase of the engine exhaust gas temperature, which is an indication for the engine thermal loading increase, and the energy of exhaust gas entering the turbocharger turbine (Figure 10c). 
__ Engine speed slope limiter A

-. - - Engine speed slope limiter C

$-\cdots-$ Engine speed slope limiter free

a)

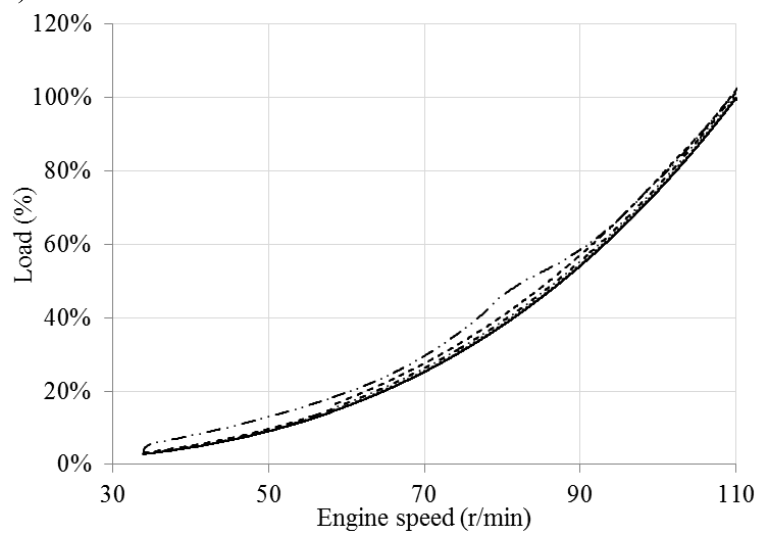

c)

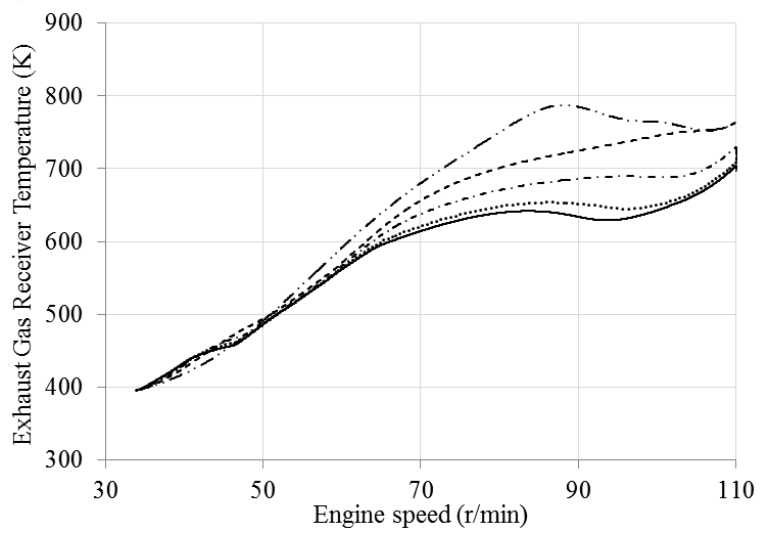

........ Engine speed slope limiter B

- - - - Engine speed slope limiter D

b)

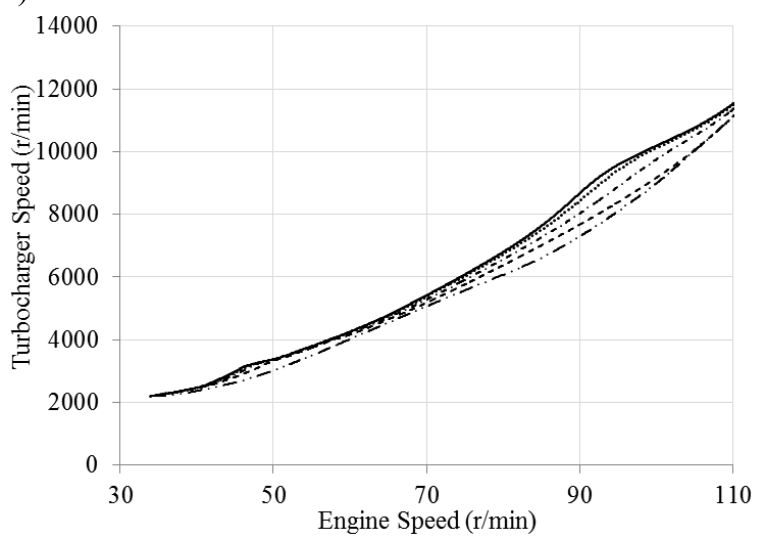

d)

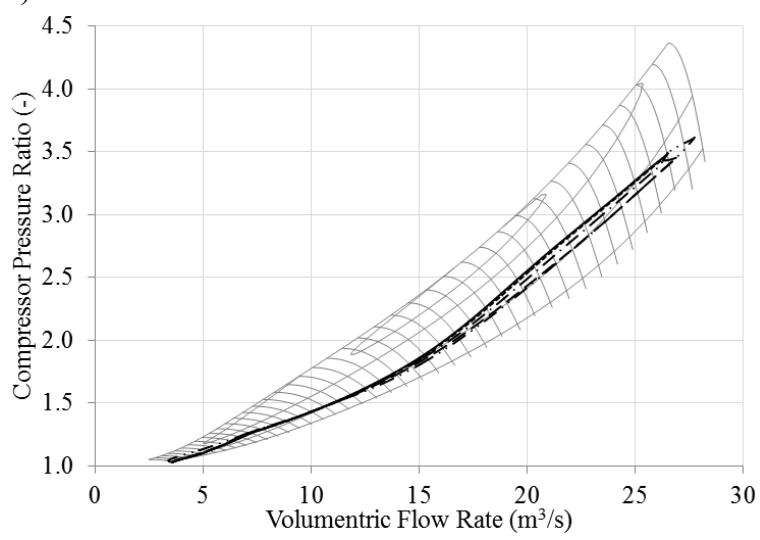

Figure 10. Variations of a) BMEP, b) Turbocharger speed, c) Exhaust gas receiver temperature versus engine speed and d) Compressor pressure ratio against air mass flow rate for various profiles of engine speed slope limiters.

The application of different engine speed slope limiters results in a different compressor performance curve as it is shown in Figure 10d. When the engine speed is low and it accelerates faster, the compressor operates with lower air flow rates for the same pressure ratio in low turbocharger speeds. In contrary, when the engine speed increases and the scavenging air limiter activates, the turbocharger speed increases faster and the compressor operation shifts to higher air flow rates. 


\section{Conclusions}

In this study, a model was developed for the simulation of a ship's propulsion system performance during acceleration manoeuvre. The tool incorporates various sub-systems, simulating the performance of the engine, the propeller and the hull hydrodynamic performance and their interaction. It succeeds to adequately estimate the overall engine and ship hydrodynamic performance during acceleration at various head sea states by using only the ordered speed and the wind speed as input variables.

An Aframax crude oil tanker was used for a case study, identifying her maximum obtainable speed for different head sea states. For the simulation of ship acceleration, an engine speed slope limiter was applied. Additionally, the model took into account the inertia of the ship and the wake profile effect at the propeller dynamics. The main findings of this work are summarized as follows:

The use of semi-empirical data and mean-value modelling approach for engine model provides an adequate accuracy for the simulation of propulsion system response during acceleration in adverse sea conditions. The validation process in steady state conditions proved that the model predictive ability is quite satisfactory with the maximum error being around $6 \%$ and $1 \%$ for the engine and hydrodynamic performance of ship propulsion system respectively. Moreover, the structure of the model had the advantage of a low computational cost and usage of limited resources for the overall prediction of the propulsion system performance.

The delayed acceleration of the ship in comparison to engine acceleration was illustrated, as well as the increase of hull resistance and reduction of engine speed when ship sails in rough seas. Furthermore, the effect of the propeller wake profile during acceleration was investigated and its impact to the propulsion system response. The tool simulated also the engine and turbocharger performance, monitoring the thermal loading of the propulsion system components during the acceleration.

Taking into account the variation of hydrodynamic performance during acceleration, the application of the engine speed slope limiter to the governor control unit was further investigated. The performed sensitivity analysis provided valuable feedback for the effect of engine slope speed limiter 
on the ship acceleration. Through this analysis, the presence of the engine governor limiters and their application timing affect the overall ship's performance. Increased engine speed slope limiter profiles lead to a faster acceleration of the engine, an increase of the exhaust gas temperature and decrease the air supply to the engine. As a result, a richer combustion takes place within cylinders, increasing the exhaust gas temperature and therefore the overall thermal loading of the engine.

In conclusion, the Propulsion System Performance Simulation (PSPS) tool predicts with low computational cost and few input variables the overall hydrodynamic performance of the propulsion system during vessel acceleration which is one of the most power demanding operation for a ship. Additionally, the effect of the control unit in the propulsion system response was investigated, highlighting the necessity of the engine governor limiters to the protection of the propulsion system components from the thermal overloading.

\section{Acknowledgements}

This work was partially supported by the "HOLISHIP - Holistic Optimisation of Ship Design and Operation for Life Cycle" project that which was funded from the European Union's Horizon 2020 research and innovation programme under grant agreement $\mathrm{N}^{\circ} 689074$. 


\section{Nomenclature}

\begin{tabular}{|c|c|}
\hline \multicolumn{2}{|c|}{ Notations } \\
\hline A & $\operatorname{area}\left(\mathrm{m}^{2}\right)$ \\
\hline $\mathrm{c}_{\mathrm{V}}$ & specific heat at constant volume $(\mathrm{J} / \mathrm{kg} / \mathrm{K})$ \\
\hline $\mathrm{D}$ & diameter (m) \\
\hline $\mathrm{f}$ & wave frequency $\left(\mathrm{s}^{-1}\right)$ \\
\hline h & specific enthalpy $(\mathrm{J} / \mathrm{kg})$ \\
\hline $\mathrm{H}$ & significant wave height (m) \\
\hline I & polar moment of inertia $\left(\mathrm{kg} \mathrm{m}^{2}\right)$ \\
\hline $\mathrm{J}$ & propeller advance speed $(\mathrm{m} / \mathrm{s})$ \\
\hline K & coefficient \\
\hline $\mathrm{K}_{\alpha}$ & proportion of entrained sea water mass in propeller \\
\hline $\mathrm{K}_{\mathrm{Q}}$ & non-dimensional torque coefficient \\
\hline $\mathrm{K}_{\mathrm{T}}$ & non-dimensional thrust coefficient \\
\hline $\mathrm{L}$ & length (m) \\
\hline $\mathrm{m}$ & $\operatorname{mass}(\mathrm{kg})$ \\
\hline$\dot{\mathrm{m}}$ & mass flow rate $(\mathrm{kg} / \mathrm{s})$ \\
\hline M & Mach number \\
\hline MWR & propeller blade mean-width ratio \\
\hline $\mathrm{N}$ & rotational speed (r/min) \\
\hline $\mathrm{p}$ & pressure $\left(\mathrm{N} / \mathrm{m}^{2}\right)$ \\
\hline $\mathrm{P}$ & Propeller pitch (m) \\
\hline$\overline{\mathrm{p}}_{\mathrm{b}}$ & break mean effective pressure $\left(\mathrm{N} / \mathrm{m}^{2}\right)$ \\
\hline $\mathrm{pr}$ & pressure ratio \\
\hline Q & torque $(\mathrm{Nm})$ \\
\hline$\dot{Q}$ & heat rate $(\mathrm{J} / \mathrm{s})$ \\
\hline $\mathrm{R}$ & gas constant $(\mathrm{J} / \mathrm{kg} \mathrm{K})$ \\
\hline $\mathrm{RR}$ & resistance $(\mathrm{N})$ \\
\hline S & spectrum form \\
\hline
\end{tabular}




\begin{tabular}{|c|c|}
\hline $\mathrm{t}$ & thrust deduction factor \\
\hline $\mathrm{T}$ & temperature $(\mathrm{K})$ \\
\hline $\mathrm{T}_{\mathrm{P}}$ & propeller thrust $(\mathrm{N})$ \\
\hline $\mathrm{u}$ & specific internal energy $(\mathrm{J} / \mathrm{kg})$ \\
\hline $\mathrm{U}$ & speed $(\mathrm{m} / \mathrm{s})$ \\
\hline V & volume $\left(\mathrm{m}^{3}\right)$ \\
\hline$\dot{\mathrm{V}}$ & volumetric flow rate $\left(\mathrm{m}^{3} / \mathrm{s}\right)$ \\
\hline$\ddot{\mathrm{V}}$ & time first derivative of volumetric flow rate $\left(\mathrm{m}^{3} / \mathrm{s}^{2}\right)$ \\
\hline $\mathrm{w}$ & wake fraction factor \\
\hline Z & number of propeller blades \\
\hline \multicolumn{2}{|c|}{ Greek symbols } \\
\hline$\gamma$ & ratio of specific heats \\
\hline$\Delta$ & difference of units \\
\hline $\mathrm{E}$ & effectiveness \\
\hline $\mathrm{H}$ & efficiency \\
\hline $\mathrm{P}$ & density $\left(\mathrm{kg} / \mathrm{m}^{3}\right)$ \\
\hline$\Phi$ & non-dimensional flow coefficient \\
\hline$\Psi$ & non-dimensional isentropic head coefficient \\
\hline \multicolumn{2}{|c|}{ Abbreviations } \\
\hline $\mathrm{a}$ & air \\
\hline A & advance \\
\hline $\mathrm{AC}$ & air cooler \\
\hline act & actual \\
\hline $\mathrm{AF}$ & air filter \\
\hline $\mathrm{amb}$ & ambient \\
\hline AWI & added wind \\
\hline AWV & added wave \\
\hline BL & blower \\
\hline $\mathrm{C}$ & compressor \\
\hline calc & calculated \\
\hline
\end{tabular}




\begin{tabular}{|c|c|}
\hline cor & corrected \\
\hline $\mathrm{CW}$ & calm water \\
\hline E & engine \\
\hline eff & effective \\
\hline ER & exhaust gas receiver \\
\hline entr & entrained \\
\hline GM & Greitzer - Moore model \\
\hline $\mathrm{H}$ & hull \\
\hline hydro & hydrodynamic added \\
\hline im & impeller \\
\hline in & inlet \\
\hline load & loading \\
\hline out & outlet \\
\hline $\mathrm{P}$ & propeller \\
\hline PM & Pierson-Moskowitz model \\
\hline $\mathrm{R}$ & rotative \\
\hline $\mathrm{S}$ & ship \\
\hline Sh & shaft \\
\hline SR & scavenging receiver \\
\hline SW & sea water \\
\hline $\mathrm{T}$ & turbine \\
\hline $\mathrm{TC}$ & turbocharger \\
\hline tot & total \\
\hline $\mathrm{W}$ & water \\
\hline wV & wave \\
\hline
\end{tabular}




\section{References}

Altosole, M., Benvenuto, G., Figari, M., Campora, U., Bagnasco, A., D'Arco, S., Giuliano, M., Giuffra, V., Spadoni, A., Zanichelli, A., Michetti, S., Ratto, M., 2008. Real time simulation of the propulsion plant dynamic behaviour of the Aircraft Carrier "Cavour". In: Proceedings of the Institute of Marine Engineering, Science and Technology Conference - INEC 2008: Embracing the Future, $8 \mathrm{p}$.

Baldi, F., Theotokatos, G., Andersson, K., 2015. Development of a Combined Mean Value-Zero Dimensional Model and Application for a Large Marine Four-stroke Diesel Engine Simulation. Applied Energy 2015. 154, 402-415.

Bazari, Z., Longva, T., 2011. Assessment of IMO Mandated Energy Efficiency Measures for International Shipping: Estimated CO2 Emissions Reduction from Introduction of Mandatory Technical and Operational Energy Efficiency Measures for Ships.

Blanke, M., Kinnaert, M., Lunze, J., Staroswiecki, M., 2006. Diagnosis and Fault-Tolerant Control. 2nd Edition, Springer. DOI:10.1007/978-3-540-35653-0.

Carlton, J.S, 2012. Marine Propellers and Propulsion. 3rd ed., Butterworth-Heinemann.

Dimopoulos, G.G., Georgopoulou, C.A., Stefanatos, I.C., Zymaris, A.S., Kakalis, N.M.P., 2014. A General-Purpose Process Modelling Framework for Marine Energy Systems. Energy Conversion and Management. 86, pp. 325-339.

Eriksson, L., 2007. Modeling and Control of Turbocharged SI and DI Engines. Oil \& Gas Science and Technology- Rev. IFP. 62-4, 523-538. DOI:10.2516/ogst:2007042.

Fujiwara, T., Ueno, M., Ikeda, Y., 2006. Cruising Performance of a Large Passenger Ship in Heavy Sea. Engineering Conference. 4, 304-311.

Guan, C., Theotokatos, G., Zhou, P., Chen, H., 2014. Computational Investigation of a Large Containership Propulsion Engine Operation at Slow Steaming Conditions. Applied Energy. 130, $370-383$.

Hasselmann, K. et al., 1973. Measurements of Wind-Wave Growth and Swell Decay during the Joint North Sea Wave Project (JONSWAP). Deutsches Hydrographisches Institut. Hamburg. 
Hendricks, E., 1986. A Compact, Comprehensive Model of Large Turbocharged, Two-Stroke Diesel Engines. SAE Technical Papers 861190.

Hountalas, D.T., 2000. Prediction of Marine Diesel Engine Performance under Fault Conditions. Applied Thermal Engineering. 20, 1753-1783.

IMO, 2013. The Marine Environment Protection Committee, Resolution MEPC.234(65), Amendments to the 2012 Guidelines on Survey and Certification of the Energy Efficiency Design Index (EEDI) (Resolution MEPC.214(63)), as amended.

IMO, 2015. The Marine Environment Protection Committee, Circular MEPC.1/Circ.850/Rev. 1, 2013 Interim Guidelines for determining minimum propulsion power to maintain the manoeuvrability of ships in adverse conditions, as amended.

ISO, 2015. BS ISO 15016, Ships and marine technology - Guidelines for the assessment of speed and power performance by analysis of speed trial data.

ITTC, 2002. The Specialist Committee on Waves Final - Report and Recommendations to the 23rd ITTC, Proceedings of 23rd ITTC.

ITTC, 2014. Recommended Procedures and Guidelines - Speed and Power Trials, Part 2 - Analysis of Speed/Power Trial Data.

Journée, J., 2001. Theoretical Manual of SEAWAY. The Netherlands.

Kyrtatos, N.P., 1999. Theodossopoulos P, Theotokatos G, Xiros N. Simulation of the overall ship propulsion plant for performance prediction and control. In: MarPower99 Conference.

Lewis, F.M., Auslaender, J., 1960. Virtual Inertia of Propellers, Journal of Ship Research. 3(4), 37-46. MAN B\&W, 2015. S60MC Project guide - propulsion.

Martelli, M., Viviani, M., Altosole, M., Figari, M., Vignolo, S., 2014. Numerical Modelling of Propulsion, Control and Ship Motions in 6 Degrees of Freedom. J. Engineering for the Maritime Environment. 228(4). p. 373-397.

McLean, M.B., 1991. Dynamic Performance of Small Diameter Tunnel Thrusters. MSc Thesis, Naval Postgraduate School.

Meuleman, C., Willems, F., de Lange, R., de Jager, B., Jun. 1998. Surge in a low-speed radial compressor. In: Proceedings at the International Gas Turbine and Aeroengine Congress. 
Stockholm, Sweden.

Minsaas, K., Faltinsen, O.M., Persson, B., 1983. On the importance of added resistance, propeller immersion and propeller ventilation for large ships in a seaway. 2nd International Symposium on Practical Design in Shipbuilding. Tokyo \& Seoul.

Moore, F.K., Greitzer, E.M., 1985. A theory of Post-Stall transients in Multistage Axial Compression Systems. NASA Contractor Report 3878, Grants NAG3-34 and NSG-3208.

Mun Pang, K., Karvounis, N., Honore Walther, J., Schramm, J., 2016. Numerical Investigation of Soot Formation and Oxidation Processes under Large Two-Stroke Marine Engine-like Conditions using integrated CFD-chemical Kinetics. Applied Energy. 169, 874-887.

Mun Pang, K., Karvounis, N., Honore Walther, J., Schramm, J., Glarborg, P., Mayer, S., 2017. Modelling of Temporal and Spatial Evolution of Sulphur Oxides and Sulphuric Acid under Large, Two-Stroke Marine Engine-like Conditions using integrated CFD-chemical kinetics. Applied Energy. 193, 60-73.

Pierson, W.J., Moskowitz, L., 1963. A proposed spectral form for fully developed wind seas based on the similarity theory of S. A. Kitaigorodskii. U.S. Naval Oceanographic Office, (N62306-1042). Raptotasios, S.I., Sakellaridis, N.F., Papagiannakis, R.G., Hountalas, D.T., 2015. Application of a Multi-Zone Combustion Model to investigate the NOx Reduction Potential of Two-Stroke Marine Diesel Engines using EGR. Applied Energy. 157, 814-823.

Rohsenow, W.M., Hartnett, J.P., Cho, Y.I., 1998. Handbook of heat transfer, third ed., McGraw-Hill, New York.

Sakellaridis, N.F., Raptotasios, S.I., Antonopoulos, A.K., Mavropoulos, G.C., Hountalas, D.T., 2015. Development and Validation of a New Turbocharger Simulation Methodology for Marine Two Stroke Diesel Engine Modelling and Diagnostic Applications. Energy. 91, 952-966.

Sargent, T.P., Kaplan, P., 1974. Modifications to Lloyds Register of Shipping Strip Theory Computer Program (LR 2570).

Schulten, P., Stapersma, D., 2003. Mean Value Modelling of the Gas Exchange of a 4-stroke Diesel Engine for Use in Powertrain Applications. SAE Technical Paper 2003-01-0219. DOI:10.4271/2003-01-0219. 
Schulten, P.J.M., 2005. The interaction between diesel engines, ship and propellers during manoeuvring. PhD Thesis. Technische Universiteit Delft, Netherlands.

Shi, W., Stapersma, D., Grimmelius, H.T., 2009. Analysis of energy conversion in ship propulsion system in off-design operation conditions. In: WIT Transactions on Ecology and the Environment. 121, 449-460.

SNAME, 1975. Marine Diesel Power Plant Performance Practices. Technical and Research Bulletin, No. 3-27. Ships' Machinery Committee, Panel M-15 (Heat Balance).

Tang, Y., Zhang, J., Gan, H., Jia, B., Xia, Y., 2017. Development of a Real-Time Two-Stroke Marine Diesel Engine Model with in-cylinder Pressure Prediction Capability. Applied Energy. 194, 5570.

Taskar, B., Koosup Yum, K., Steen, S., Pedersen, E., 2017. The effect of waves on engine-propeller dynamics and propulsion performance of ships. Ocean Engineering. 122, 262-277.

Theotokatos, G.P., 2008. Ship Propulsion Plant Transient Response Investigation using a Mean Value Engine Model. International Journal of Energy. 2-4, 66-74.

Theotokatos, G., 2010. On the cycle mean value modelling of a large two-stroke marine diesel engine. Proceedings of the Institution of Mechanical Engineers, Part M: Journal of Engineering for the Maritime Environment. 224(3), 193-205.

Theotokatos, G., Tzelepis, V., 2015. A computational study on the performance and emission parameters mapping of a ship propulsion system. Proceedings of the Institution of Mechanical Engineers, Part M: Journal of Engineering for the Maritime Environment. 229(1), 58-76.

Tsakonas, S., 1958. Analytical Expressions for Thrust Deduction and Wake Fraction for Potential Flows. Ship Research.50-59.

van den Boom, H., Huisman, H., Mennen, F., 2013. New Guidelines for Speed/Power Trials. Level playing field established for IMO EEDI. SWZ Maritime. pp. 1-11.

van Helvoirt, J., 2007. Centrifugal Compressor Surge: Modelling and Identification for Control. Ph.D. Thesis. Technische Universiteit Eindhoven. Eindhoven. The Netherlands.

Viviani, M., Altosole, M., Cerruti, M., Menna, A., Dubbioso, G., Sep. 2008. Marine propulsion system dynamics during ship manoeuvres. In: 6th International Conference on high-performance 
marine vehicles (Hiper 2008). pp. 81-93.

White, F.M., 2009. Fluid mechanics. 7th edition. McGraw-Hill.

Willems, F.P.T., 2000. Modelling and Bounded Feedback Stabilization of Centrifugal Compressor Surge. Ph.D. Thesis. Technische Universiteit Eindhoven, Eindhoven, The Netherlands.

WMO, 1970. Beaufort Scale of Wind Force (Technical and operational aspects). Commission for Marine Meteorology. Report on Marine Science Affairs No.3. Geneva.

Woodward, J.B., Latorre, R.G., 1984. Modeling of Diesel Engine Transient Behavior in Marine Propulsion Analysis. SNAME Transactions. 92, 33-49.

Xiros, N.I., Theotokatos, G., Oct. 2011. Improved transient control of a two-stroke marine diesel engine with variable geometry turbine. In: Proceedings of the ASME 2011 Internal Combustion Engine Division Fall Technical Conference (ICEF2011). Morgantown, West Virginia, USA.

Yoerger, D.R., Cooke, J.G., Slotine, J.J.E., 1990. The Influence of Thruster Dynamics on Underwater Vehicle Behaviour and Their Incorporation into Control System Design. IEEE Journal of Oceanic Engineering. 15(3), 167-178.

Zhao, F., Yang, W., Wan Tan, W., Kiang Chou, S., Yu, W., 2015. An Overall Ship Propulsion Model for Fuel Efficiency Study. Energy Procedia. 75(65), 813-818. 